\title{
Spectral hole burning: examples from photosynthesis
}

\author{
Robin Purchase $\cdot$ Silvia Völker
}

Received: 15 June 2009/ Accepted: 31 July 2009/Published online: 28 August 2009

(c) The Author(s) 2009. This article is published with open access at Springerlink.com

\begin{abstract}
The optical spectra of photosynthetic pigmentprotein complexes usually show broad absorption bands, often consisting of a number of overlapping, 'hidden' bands belonging to different species. Spectral hole burning is an ideal technique to unravel the optical and dynamic properties of such hidden species. Here, the principles of spectral hole burning (HB) and the experimental set-up used in its continuous wave $(\mathrm{CW})$ and time-resolved versions are described. Examples from photosynthesis studied with hole burning, obtained in our laboratory, are then presented. These examples have been classified into three groups according to the parameters that were measured: (1) hole widths as a function of temperature, (2) hole widths as a function of delay time and (3) hole depths as a function of wavelength. Two examples from light-harvesting (LH) 2 complexes of purple bacteria are given within the first group: (a) the determination of energy-transfer times from the chromophores in the B800 ring to the B850 ring, and (b) optical dephasing in the B850 absorption band. One example from photosystem II (PSII) sub-core complexes of higher plants is given within the second group: it shows that the size of the complex determines the amount of spectral diffusion measured. Within the third group, two examples from (green) plants and purple bacteria have been chosen for: (a) the identification of 'traps' for energy transfer in PSII sub-core complexes of green plants, and (b) the uncovering of the lowest $k=0$ exciton-state
\end{abstract}

R. Purchase · S. Völker

Huygens and Gorlaeus Laboratories, Leiden University, 2300

RA Leiden, The Netherlands

S. Völker $(\bowtie)$

Department of Biophysics, Faculty of Exact Sciences, Vrije Universiteit Amsterdam, 1081 HV Amsterdam, The Netherlands

e-mail: silvia@molphys.leidenuniv.nl distribution within the $\mathrm{B} 850$ band of $\mathrm{LH} 2$ complexes of purple bacteria. The results prove the potential of spectral hole burning measurements for getting quantitative insight into dynamic processes in photosynthetic systems at low temperature, in particular, when individual bands are hidden within broad absorption bands. Because of its highresolution wavelength selectivity, $\mathrm{HB}$ is a technique that is complementary to ultrafast pump-probe methods. In this review, we have provided an extensive bibliography for the benefit of scientists who plan to make use of this valuable technique in their future research.

Keywords Hole burning - Energy transfer .

Hidden absorption bands .

Light-harvesting complex 2: B800, B850 - Energy traps .

Photosystem II core complexes

$\begin{array}{ll}\text { Abbreviations } \\ \text { A } & \text { Area of the laser beam on the sample } \\ \text { AOM } & \text { Acousto-optic modulator } \\ \text { APE } & \text { Accumulated photon echo } \\ \text { BChl } a & \text { Bacteriochlorophyll } a \\ \text { Chl } a & \text { Chlorophyll } a \\ \text { CS } & \text { Conformational sub-state } \\ \text { CW } & \text { Continuous wave } \\ \text { EOM } & \text { Electro-optic modulator } \\ \text { FLN } & \text { Fluorescence line-narrowing } \\ \text { FP } & \text { Fabry-Perot } \\ \text { FSR } & \text { Free spectral range } \\ \text { HB } & \text { Hole burning } \\ \text { LH2 } & \text { Light-harvesting (complex) } 2 \\ \text { LIS } & \text { Light-intensity stabilization } \\ \text { NPHB } & \text { Non-photochemical hole burning } \\ \text { OG } & n \text {-Octyl- } \beta \text {-glucopiranoside }\end{array}$




$\begin{array}{ll}P & \text { Power of the laser } \\ \text { P/A } & \text { Power/area: power density } \\ \text { PC } & \text { Personal computer } \\ \text { PD } & \text { Photodiode } \\ \text { PHB } & \text { Photochemical hole burning } \\ \text { Pheo } a & \text { Pheophytin } a \\ \text { PM } & \text { Photomultiplier } \\ \text { PSII } & \text { Photosystem II } \\ \text { Pt/A } & \text { Power, with burning time, t/area:burning-fluence } \\ & \text { density } \\ \text { RC } & \text { Reaction center } \\ \text { SD } & \text { Spectral diffusion } \\ T & \text { Temperature } \\ t & \text { Time } \\ \text { THB } & \text { Transient hole burning } \\ \text { TLS } & \text { Two-level system }\end{array}$

\section{Introduction}

Frequency- and time-resolved laser spectroscopic techniques play an important role in the study of relaxation processes of electronically excited states of photosynthetic pigment-protein complexes. Energy transfer between pigments, optical dephasing, spectral diffusion and decay of exciton states are examples of such relaxation processes. To study these processes, lasers are used that have either very short pulses or very narrow spectral widths.

Techniques that make use of narrow-band lasers are called site- or energy-selective spectroscopies (Gooijer et al. 2000), such as fluorescence line-narrowing (FLN; Creemers et al. 1999a; De Caro et al. 1994; Freiberg et al. 2009; Jankowiak 2000; Personov 1983; Personov et al. 1972; Peterman et al. 1997), spectral hole burning (HB; Creemers and Völker 2000; Dang et al. 2008; De Vries and Wiersma 1976; Friedrich et al. 1994; Gorokhovskii et al. 1974; Hayes and Small 1978; Kharlamov et al. 1974; Krausz et al. 2008; Moerner 1988, and articles therein; Reinot et al. 2001; Völker 1989a, b; Völker and Van der Waals 1976) and single-molecule (SM) spectroscopy (Barkai et al. 2004; Berlin et al. 2007; Cogdell et al. 2006; Ketelaars et al. 2001; Moerner 2002; Moerner and Kador 1989; Orrit and Bernard 1990; Rigler et al. 2001; Rutkauskas et al. 2004, 2006; Van Oijen et al. 1999). These experimental methods yield information on dynamic processes in doped crystals and glasses as well as in pigmentprotein complexes that cannot be obtained with conventional spectroscopy since their homogeneously broadened bands are buried under largely inhomogeneously broadened spectra.
This educational review is focussed on spectral hole burning (HB); it also provides an extensive bibliography. After an introduction to the processes studied here, we describe the HB principle. This is followed by a discussion of experimental methods. We then demonstrate the potential of this technique to obtain an insight into the dynamics of photosynthetic systems after photo-excitation. A number of examples, obtained in our laboratory, are shown (for references, see below). We prove that information on energy-transfer times and optical dephasing can be obtained for light-harvesting ( $\mathrm{LH}$ ) complexes of purple bacteria by measuring the hole width as a function of temperature. The first example discusses the B800-to-B850 energy-transfer process in LH2 complexes, whereas the second example shows results of optical dephasing in the red wing of the B850 band of $\mathrm{LH} 2$. We then follow this discussion on the broadening of the hole as a function of time (spectral diffusion). We show that the amount of spectral diffusion depends on the size of the photosynthetic complex studied. Further, we demonstrate that, in addition to the hole width, the hole depth as a function of wavelength can also yield relevant information that is otherwise hidden under the broad absorption bands. Data reviewed proves the existence of 'traps' for energy transfer in photosystem II (PSII) sub-core complexes of higher plants. The final example shows how we uncovered the lowest $k=0$ exciton states hidden under the B850 band of LH2 complexes, and how their spectral distributions could be determined. To our knowledge, HB is the only technique that is able to uncover small, hidden spectral distributions characterized by specific dynamics.

Homogeneous linewidths, optical dephasing and spectral diffusion

Absorption and emission bands of pigment-protein complexes and organic molecules dissolved in solvents or polymers are generally very broad (typically a few $100 \mathrm{~cm}^{-1}$, even at liquid-He temperatures), as compared to those found in crystalline systems (of a few $\mathrm{cm}^{-1}$ ). Such large widths are caused by the slightly different environments of the individual chromophores within the disordered host (the protein or glass at low temperature), leading to a broad statistical distribution of the electronic transition energies and, therefore, to a wide Gaussian profile with an inhomogeneous width $\Gamma_{\text {inh }}$ (Creemers and Völker 2000; Völker 1989a, b, and references therein).

Information on the dynamics of the excited state of the system is contained in the homogeneous linewidth $\Gamma_{\text {hom }}$ of the electronic transition of the individual chromophores. Since $\Gamma_{\text {hom }}$ is usually a factor of $10^{3}-10^{5}$ times smaller than $\Gamma_{\text {inh }}$ (Völker 1989a, b), the homogeneous line is buried in the inhomogeneously broadened band. To obtain 
the value of $\Gamma_{\text {hom }}$, laser techniques must be used, either in the time domain, such as photon echoes (Agarwal et al. 2002; Fidder and Wiersma 1993; Fidder et al. 1998; Hesselink and Wiersma 1980, 1983; Jimenez et al. 1997; Lampoura et al. 2000; Narasimhan et al. 1988; ThornLeeson and Wiersma 1995; Thorn-Leeson et al. 1997; Wiersma and Duppen 1987; Yang and Fleming 1999), or in the frequency domain, such as FLN, HB and SM (for references, see above).

The lineshape of a homogeneously broadened electronic transition is usually Lorentzian; it is the Fourier-transform of an exponential decay function. Its linewidth $\Gamma_{\text {hom }}$ is given by the inverse of the optical dephasing time $T_{2}$ and is usually written as the sum of two terms (Völker 1989a, b; Wiersma and Duppen 1987):

$\Gamma_{\text {hom }}=\frac{1}{\pi T_{2}}=\frac{1}{2 \pi T_{1}}+\frac{1}{\pi T_{2}^{*}(T)}$,

where $T_{1}$ is the lifetime of the electronically excited state and $T_{2}^{*}$ is the 'pure' dephasing time. The first term in Eq. 1 does not depend on temperature $T$, at low $T$. It is called the residual linewidth $\Gamma_{0}=\left(2 \pi T_{1}\right)^{-1}$ for $T \rightarrow 0$. $T_{2}^{*}$ represents the time it takes for the coherence of the electronic transition to be destroyed by chromophore-host (or pigment-protein) interactions. Since such fluctuations of the optical transition are caused by phonon scattering, $T_{2}^{*}$ depends on $T$.

The functional dependence on temperature of the second term $\left(\pi T_{2}^{*}(T)\right)^{-1}$ in Eq. 1 differs for crystalline and amorphous systems. For doped organic crystals, it depends exponentially on temperature as exp $(-E / \mathrm{k} T)$ (Dicker et al. 1981; Molenkamp and Wiersma 1984; Morsink et al. 1977; Völker 1989a, b; Völker et al. 1977, 1978). For doped organic glasses and pigment-protein complexes, it follows a universal $T^{1.3 \pm 0.1}$ power law at low temperature ( $T \leq 20 \mathrm{~K}$ ), independent of the host and the chromophore (Breinl and Friedrich 1988; Jankowiak and Small 1993; Jankowiak et al. 1993; Köhler et al. 1988; Meijers and Wiersma 1994; Narasimhan et al. 1988; Thijssen et al. 1982, 1983, 1985; Van den Berg and Völker 1986, 1987; Van den Berg et al. 1988; Völker 1989a, b). Such a $T$ dependence has been interpreted in terms of two-level systems (TLS), which are low-energy excitations assumed to exist in glasses and in disordered systems in general. The TLSs are double-well potentials representing distinct structural configurations of the glass (Anderson et al. 1972; Phillips 1972, 1981, 1987). The transition or 'flipping' from one potential well to another occurs through interaction with phonons that cause a change in the glassy structure. TLSs are assumed to have a broad distribution of tunnelling parameters and energy splittings that lead to a broad distribution of fluctuation rates in the glass (Black and Halperin 1977; Hu and Walker 1977, 1978; Jankowiak et al. 1986; Maynard et al. 1980). If a probe molecule is incorporated in such a disordered host and its optical transition couples to TLSs, the dephasing or frequency fluctuations of the optical transition will be caused by relaxation of the TLSs. In particular, 'fast' TLSs that have relaxation rates $\mathrm{R}$ much larger than the decay rate $\left(1 / T_{1}\right)$ of the excited state of the probe molecule are assumed to be responsible for 'pure' dephasing. The $T^{1.3}$ dependence of $\Gamma_{\text {hom }}$ has been explained by assuming a dipole-dipole coupling between the probe molecule and TLSs, with a density of states of the TLSs varying as $\rho(E) \propto E^{0.3}$, where $E$ is the energy splitting of the eigenstates of the TLSs (Huber 1987; Jankowiak and Small 1993; Jankowiak et al. 1993; Putikka and Huber 1987).

The evolution of the glass (or protein) dynamics may lead to a continuous and irreversible change of the frequency of the optical transition of the chromophore. As a consequence, the observed homogeneous linewidth will depend on the time delay $\left(t_{\mathrm{d}}\right)$ between the excitation of the transition and its observation (Bai and Fayer 1988, 1989). This process is called spectral diffusion (Creemers et al. 1997; Den Hartog et al. 1998a, 1999a, b; Friedrich and Haarer 1986; Koedijk et al. 1996; Littau et al. 1992; Lock et al. 1999; Meijers and Wiersma 1994; Silbey et al. 1996; Wannemacher et al. 1993), and the measured width is the 'effective' homogeneous linewidth $\Gamma_{\text {hom. }}^{\prime}$. In a time-dependent hole-burning experiment (see below) $\Gamma_{\text {hom }}^{\prime}$ depends on the delay $t_{\mathrm{d}}$ between the burn and probe pulse.

Principles of hole burning

In a spectral hole-burning experiment, the inhomogeneously broadened absorption band is irradiated at a given wavelength with a narrow-band laser. Whenever the molecules resonant with the laser wavelength undergo a phototransformation (photophysical or photochemical), a hole is created in the original absorption band (see Fig. 1). The width of the hole, under certain conditions (see below), is then proportional to the homogeneous linewidth. The photoproduct will absorb at a different wavelength, either within the absorption band or outside. Since the laser selects molecules absorbing at a given frequency $v_{1}$, and not molecules in a specific environment, the correlation between transition energy and environmental parameters is, in general, different for the photoproduct and the original molecule. As a consequence, the width of the photoproduct band, or antihole, is larger than that of the hole (Völker and Van der Waals 1976; Völker and Macfarlane 1979). The optical resolution that can be reached with $\mathrm{HB}$ is $10^{3}-10^{5}$ times higher than that with conventional techniques, which makes $\mathrm{HB}$ a powerful tool for spectroscopy in the $\mathrm{MHz}$ range (Völker 1989a, b). 

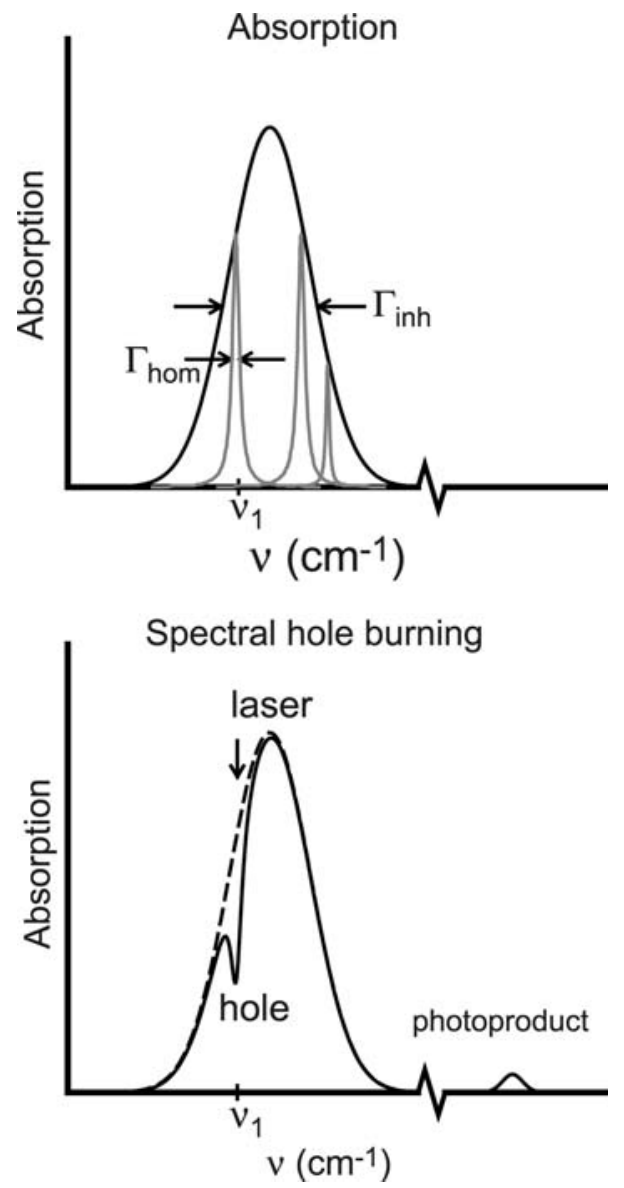

Fig. 1 Top: Diagram of an inhomogeneously broadened absorption band with a width $\Gamma_{\text {inh }}$. The homogeneous bands of width $\Gamma_{\text {hom }}$ of the individual electronic transitions are hidden under the broad inhomogeneous absorption band. Bottom: Laser-induced spectral hole burned at frequency $v_{1}$. The photoproduct absorbs at a different frequency, here outside the inhomogeneous band (Creemers and Völker 2000)

Hole-burning mechanisms can be divided into two categories: persistent $\mathrm{HB}$ and transient $\mathrm{HB}$ (THB). Within the first category, there is photochemical HB (PHB; De Vries and Wiersma 1976; Friedrich and Haarer 1986, and references therein; Völker and Van der Waals 1976; Völker et al. 1977) and non-photochemical HB (NPHB; Carter and Small 1985; Hayes and Small 1978; Jankowiak and Small 1987, and references therein; Small 1983). The time scales involved in PHB and NPHB at low temperature are usually seconds to hours, whereas THB often lasts only microseconds $(\mu \mathrm{s})$ or milliseconds $(\mathrm{ms})$. For more details about these HB mechanisms, the reader is referred to Völker (1989a, b).

Dynamic processes, such as optical dephasing, energy transfer and spectral diffusion, which determine the homogeneous linewidth and therefore the hole width, depend on the interaction of the optical transition of the probe molecule with its surroundings. Thus, the hole width does not depend on the HB mechanism, as long as the latter takes place at a time scale much larger than the dynamic process under study (Creemers et al. 1997; Koedijk et al. 1996).

\section{Experimental methods}

A hole-burning (HB) experiment consists of three steps, schematically shown in Fig. 2: (1) the laser is scanned with low light intensity for a time $t_{\mathrm{p}}$ over the wavelength range of interest to generate a baseline in the absorption band; (2) a hole is burnt at a fixed wavelength for a time $t_{\mathrm{b}}$ with a much higher laser intensity (typically a factor of $10-10^{3}$ ); (3) the hole is probed for a time $t_{\mathrm{p}}$ by scanning the laser with low intensity as in step (1). To obtain the hole profile, the difference is taken between the signals in steps (1) and (3). To study spectral holes as a function of time (spectral diffusion), the delay time $t_{\mathrm{d}}$ is varied. Every new hole is then burnt at a slightly different wavelength in a spectral region outside of the previous scan region (Creemers and Völker 2000; Den Hartog et al. 1999b; Völker 1989a, b).

Experimental set-up for continuous-wave hole burning

The experimental set-up used in our laboratory to perform CW hole-burning experiments is depicted in Fig. 3a. A single-frequency, $\mathrm{CW}$ titanium:sapphire ring laser (bandwidth $\sim 0.5 \mathrm{MHz}$, tunable from $\sim 700$ to $1,000 \mathrm{~nm}$ ) or a dye laser (bandwidth $\sim 1 \mathrm{MHz}$, tunable between $\sim 550$ and $700 \mathrm{~nm})$, both pumped by an $\mathrm{Ar}^{+}$laser $(2-15 \mathrm{~W})$, is

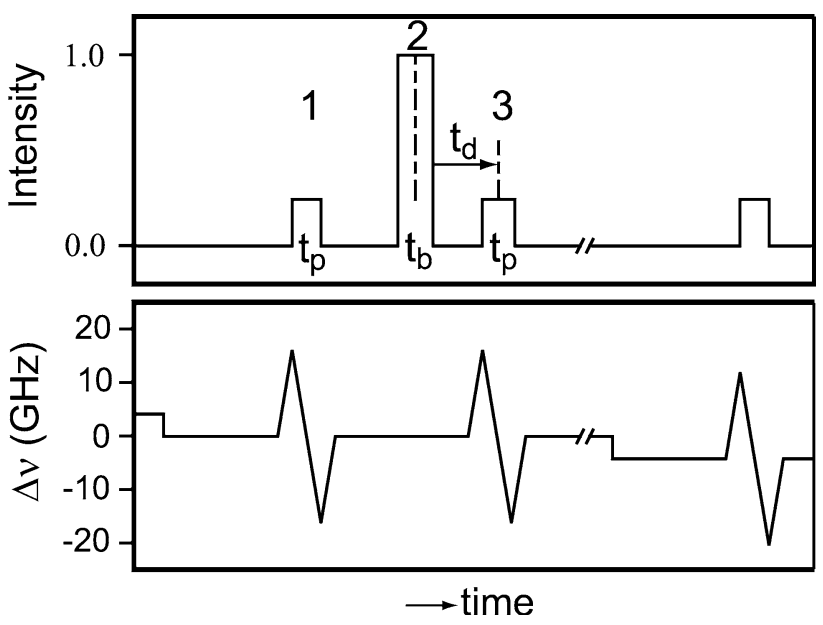

Fig. 2 Pulse sequence used in time-resolved hole-burning (HB) experiments. Top: Timing of the laser pulses with $t_{\mathrm{p}}$ : probe time, $t_{\mathrm{b}}$ : burn time and $t_{\mathrm{d}}$ : delay time. Bottom: Frequency ramp and steps with $\Delta v$ : change in laser frequency (Den Hartog et al. 1999b) 
used. The intensity of the laser light is stabilized with a feedback loop consisting of an electro-optic modulator (EOM), a photodiode (PD) and control circuitry for LightIntensity Stabilization (LIS). The wavelength of the laser is calibrated with a wavemeter (resolution $\Delta \lambda / \lambda \sim 10^{-7}$ ) and the mode structure of the laser is monitored with a confocal Fabry-Perot (FP) etalon (free spectral range, FSR = $300 \mathrm{MHz}, 1.5 \mathrm{GHz}$ or $8 \mathrm{GHz}$ ). Burning power densities $P / A$ ( $P$ is the power of the laser, and $A$ is the area of the laser beam on the sample) between $\sim 1 \mu \mathrm{W} / \mathrm{cm}^{2}$ and a few $100 \mu \mathrm{W} / \mathrm{cm}^{2}$, with burning times $t_{\mathrm{b}}$ from $\sim 5$ to $\sim 100 \mathrm{~s}$, are generally used.
The holes are either probed in fluorescence excitation at $90^{\circ}$ to the direction of excitation or in transmission through the sample, with the same laser but with the power attenuated by a factor of $10-10^{3}$. The intensity of the probe pulse is reduced with a neutral density filter. The fluorescence or transmission signal of the hole is detected with a cooled photomultiplier (PM) and subsequently amplified with an electrometer. The signals are digitized and averaged point by point 1,000 times with a computer (PC) and the pulse scheme of Fig. 2 is used only once and not cycled through (see below). The experiments are controlled with a PC (Creemers and Völker 2000; Völker 1989a, b).
Fig. 3 Top: a Set-up for $C W$ hole burning. Either a $\mathrm{CW}$ (continuous wave), singlefrequency titanium-sapphire (bandwidth $0.5 \mathrm{MHz}$ ) or a dye laser (bandwidth 1-2 $\mathrm{MHz}$ ) was used. EOM electro-optic modulator, LIS electronic control circuit for light-intensity stabilization, $B S$ beam splitter, $P D$ photodiode, $P L$ polarizer, $\lambda$ meter Michelson interferometer, FP Fabry-Perot etalon, $M$ mirror, $O D$ neutral density filters, $S h$ shutter, $L$ lens, $S$ sample, $C$ liquid- ${ }^{4} \mathrm{He}$-cryostat, $P M$ (cooled) photomultiplier, $A D C$ analogue-to-digital converter, DAC digital-toanalogue converter. Bottom: b Time-resolved hole-burning setup. Either a CW singlefrequency temperature- and current-controlled $(T$ - and I-control) diode laser, or a titanium:sapphire laser, or a dye laser (see the above panel, a) was used. $O I$ optical isolator, AOM/D acousto-optic modulator and driver, $A$ diaphragm, Amp amplifier, $P \& D$ GEN pulse- and delay generator, WF GEN waveform synthesiser, $\oplus$ summing amplifier, DIG SCOPE digital oscilloscope, PIA peripheral interface adapter (Adapted from Creemers and Völker 2000)

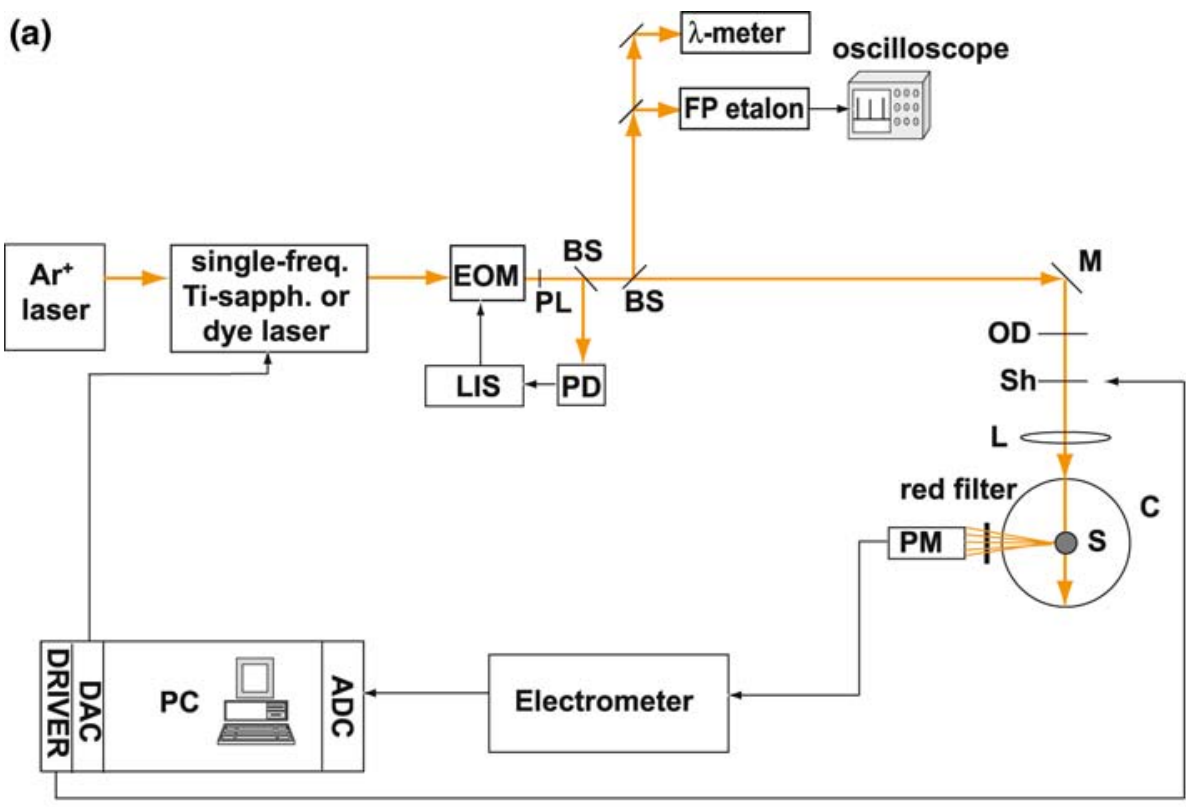

(b)

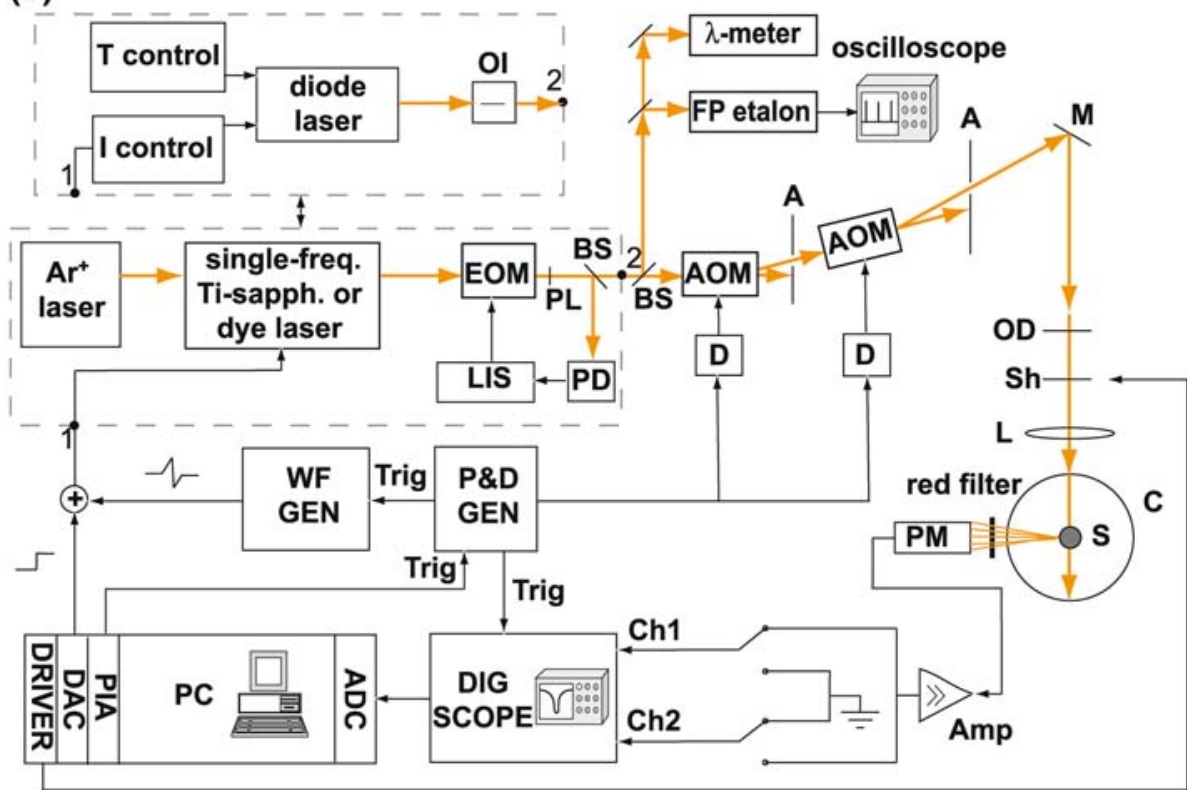


Experimental set-up for time-resolved hole burning

To perform time-resolved hole-burning experiments (see Fig. 3b), various types of CW single-frequency lasers are used, in combination with acousto-optic modulators (AOMs), to create the pulse sequence described in Fig. 2. The choice of the laser depends on the absorption wavelength of the sample and the time scale of the experiment (Creemers and Völker 2000; Creemers et al. 1997; Den Hartog et al. 1998a, 1999a, b; Koedijk et al. 1996; Störkel et al. 1998; Wannemacher et al. 1993). For delay times $t_{\mathrm{d}}$, shorter than a few $100 \mathrm{~ms}$ and down to microseconds, we use current- and temperature-controlled single-mode diode lasers. The type of diode laser depends on the wavelength needed. The main advantage of these semiconductor lasers is that their frequency can be scanned very fast, up to $\sim 10 \mathrm{GHz} / \mu \mathrm{s}$, by sweeping the current through the diode. A disadvantage is their restricted wavelength region (5$10 \mathrm{~nm}$, tunable by changing the temperature of the laser). The bandwidth of these diode lasers is $\sim 3 \mathrm{MHz}$ (Den Hartog et al. 1999b). For delay times $t_{\mathrm{d}}$ longer than $\sim 100 \mathrm{~ms}$, either a CW single-frequency titanium:sapphire (bandwidth $\sim 0.5 \mathrm{MHz}$ ) or a dye laser (bandwidth $\sim 1 \mathrm{MHz}$ ) is used. The frequency of these lasers can be scanned continuously over $30 \mathrm{GHz}$ with a maximum scan speed limited to $\sim 100 \mathrm{MHz} / \mathrm{ms}$ by piezoelectric-driven mirrors. This speed is about $10^{4}-10^{5}$ times slower than that of diode lasers (Creemers and Völker 2000; Den Hartog et al. 1999b).

Burning power densities $(P t / A)$ between $\sim 50 \mathrm{nW} / \mathrm{cm}^{2}$ and $20 \mathrm{~mW} / \mathrm{cm}^{2}$, with burning times $t_{\mathrm{b}}$ ranging from $1 \mu \mathrm{s}$ to $\sim 100 \mathrm{~s}$, are generally used. The delay time $t_{\mathrm{d}}$ between burning and probing the holes varies from $\sim 1 \mu \mathrm{s}$ to $\sim 24 \mathrm{~h}$. For delay times shorter than $\sim 100 \mathrm{~s}$, the burn and probe pulses are produced with two AOMs in series (two instead of one to reduce the laser light leaking through them when switched off, suppression better than $10^{6}$ ). For delay times $t_{\mathrm{d}}$ longer than $\sim 100 \mathrm{~s}$, the intensity of the probe pulse is reduced with a neutral density filter.

The holes are probed in fluorescence excitation with a cooled photomultiplier (PM) perpendicular to the direction of excitation. The signals before and after burning are stored in two channels of a digital oscilloscope, amplified and averaged in different ways, depending on delay time. For $t_{\mathrm{d}}<100 \mathrm{~ms}$, a sequence of probe-burn-probe cycles is applied with a repetition rate $\leq 10 \mathrm{~Hz}$ using home-built electronics (see Fig. 3b) and then summed. After each probe-burn-probe cycle, the frequency of the laser is slightly shifted (by a few times the hole width) to obtain a fresh baseline for each hole. Transient holes with a lifetime up to a few milliseconds are averaged $10^{3}-10^{4}$ times, whereas persistent holes with delay times shorter than $\sim 100 \mathrm{~s}$ are averaged 50-100 times with the digital oscilloscope. For delay times $t_{\mathrm{d}}>100 \mathrm{~s}$, the signals are averaged point by point about 1,000 times with the $\mathrm{PC}$, with a total number of 200-1000 points per scan, depending on $t_{\mathrm{d}}$ (see previous section). Experiments are controlled with the PC.

\section{Examples from photosynthesis studied with hole burning}

Energy transfer and optical dephasing: hole width as a function of temperature

Examples presented below will show how energy-transfer times and information on optical dephasing can be obtained for light-harvesting ( $\mathrm{LH})$ complexes of purple bacteria by measuring the hole width as a function of temperature. $\mathrm{LH}$ complexes (antennas) in photosynthetic systems are responsible for the efficient collection of sunlight and the transfer of excitation energy to the reaction center (RC). The primary charge separation, which occurs in the RC, leads to the subsequent conversion of the excitation energy into a chemically useful form. The function of the antenna is to improve the absorption cross-section of the individual RCs. Each RC is surrounded by many LH complexes (Blankenship 2002; Sundström et al. 1999; Van Amerongen et al. 2000; Van Grondelle et al. 1994).

Most purple bacteria contain two types of $\mathrm{LH}$ complexes: the LH1 core complex surrounding each $\mathrm{RC}$, and peripheral LH2 complexes that absorb slightly to the blue and transfer energy to LH1 (Cogdell et al. 2006; Fleming and Scholes 2004; Hu et al. 2002; Sundström et al. 1999; Van Amerongen et al. 2000; Van Grondelle and Novoderezhkin 2006). Both the LH1 and the LH2 complexes have concentric ring-like structures. The LH1 complex has only one absorption band at $\sim 875 \mathrm{~nm}$. In contrast, the LH2 complex of Rhodobacter ( $R b$.) sphaeroides (discussed below) has two absorption bands at 800 and $850 \mathrm{~nm}$, as shown in Fig. 4 (bottom). The pigments in these purple bacteria are bacteriochlorophyll $a$ (BChl $a$ ) molecules and carotenoids non-covalently bound to a pair of small transmembrane $\alpha$ and $\beta$ polypeptides. The B800 ring in Rhodopseudomonas (Rps.) acidophila consists of nine in-plane BChl $a$ monomers, whereas the B850 ring is formed by a collection of 18 BChls distributed along the ring in 9 dimer subunits (McDermott et al. 1995; Papiz et al. 2003). Their planes are perpendicular to those of the BChls in the B800 ring (see Fig. 4, top). The X-ray structure of Rhodosprillum (Rs) molischianum is similar to that of Rps. acidophila, with 8 BChls in the $\mathrm{B} 800$ ring and 16 BChls in B850 (Koepke et al. 1996). Cryoelectron microscopy has shown that the structure of the LH2 complex of $R b$. sphaeroides (Walz et al. 1998) is also similar to that of Rps. acidophila. 
Rb. sphaeroides 2.4 .1 (w.t.)
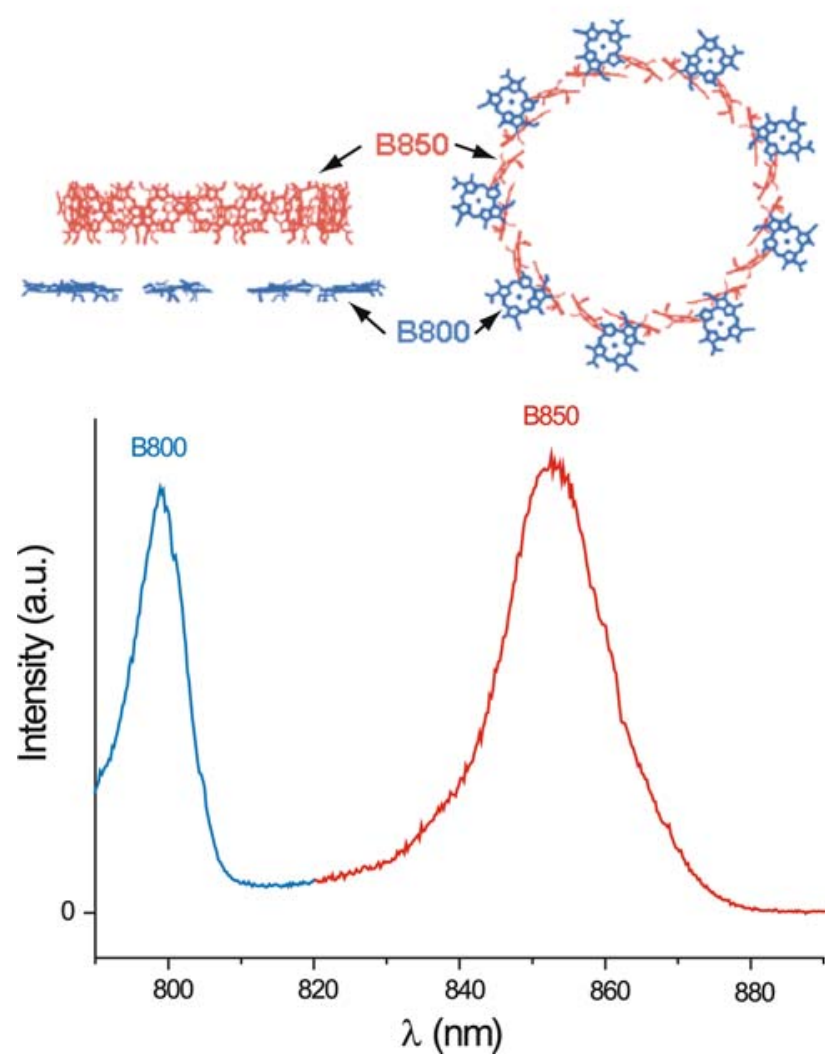

Fig. 4 Top: Arrangement of the bacteriochlorophyll $a$ (BChl $a$ ) molecules in the B800 and B850 rings of the light-harvesting (LH) 2 complex (left: side view, right: top view; Data from www.pdb.bnl.gov.) Bottom: Excitation spectrum of the LH2 complex of $R b$. sphaeroides $(2.4 .1$, wt) at liquid-helium temperature (Spectrum obtained in our laboratory)

\section{Energy transfer from B800 to B850 in light-harvesting 2 complexes of purple bacteria}

The wavelength selectivity and high-frequency resolution of spectral hole burning is particularly advantageous for the study of pigment-protein complexes that are characterized by broad absorption bands. The first HB experiments on photosynthetic complexes were performed by G. Small and his group in the 1980s on the RC of purple bacteria (Hayes and Small 1986; Lyle et al. 1993, and references therein; Tang et al. 1988), and on photosystem I (Gillie et al. 1989) and the RC of photosystem II (Jankowiak et al. 1989; Tang et al. 1990) of green plants and cyanobacteria. Here, we describe HB experiments performed in our laboratory, in Leiden, The Netherlands, on the red wing of the B800 band of LH2 at liquid-helium temperature (De Caro et al. 1994; Van der Laan et al. 1990, 1993). The results of these experiments proved, for the first time, that the B800 band is inhomogeneously broadened because holes could be burned into this band. As described earlier in this review, the widths of spectral holes are a measure for the homogeneous linewidth $\Gamma_{\text {hom }}$ of the optical transition, under the condition that the laser bandwidth is negligible compared

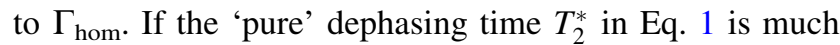
larger than $T_{1}$, i.e. $T_{2}^{*} \gg T_{1}$, then $\Gamma_{\text {hom }}$ will be determined by $T_{1}$ processes. Thus,

$\Gamma_{\text {hom }} \approx \frac{1}{2 \pi T_{1}}=\frac{1}{2 \pi \tau_{\mathrm{fl}}}+\frac{1}{2 \pi \tau_{\mathrm{ET}}}$,

where $\tau_{\mathrm{fl}}$ is the fluorescence lifetime, and $\tau_{\mathrm{ET}}$ is the energytransfer time. If the latter is much shorter than $\tau_{\mathrm{ff}}$, for example, $\tau_{\mathrm{ET}}$ approximately a few picoseconds, $\Gamma_{\text {hom }}$ will directly yield the energy-transfer rate $\left(2 \pi \tau_{\mathrm{ET}}\right)^{-1}$.

In the experiments of De Caro et al. (1994) and Van der Laan et al. (1990), where holes were burnt into the red wing of the B800 band of $R b$. sphaeroides 2.4.1 (wild type, wt), hole widths were found of $1 / 2 \Gamma_{\text {hole }}=\Gamma_{\text {hom }} \sim 65 \mathrm{GHz}$, independent of burning wavelength between 791 and $804 \mathrm{~nm}$. Since this width is much larger than the fluorescence lifetime-limited value, $\left(2 \pi \tau_{\mathrm{ff}}\right)^{-1} \sim 100 \mathrm{MHz}$ (corresponding to a $\tau_{\mathrm{fl}}$ of a few ns), and the value of $\Gamma_{\text {hom }}$ proved independent of temperature between $\sim 1.2$ and $30 \mathrm{~K}$ (no holes could be burnt at $T>30 \mathrm{~K}$ ), Van der Laan et al. (1990) concluded that $\Gamma_{\text {hom }}$ is entirely given by the energytransfer rate from $\mathrm{B} 800$ to $\mathrm{B} 850$, which corresponds to $\tau_{\mathrm{B} 800 \rightarrow \mathrm{B} 850}=2.3( \pm 0.4)$ ps. In Fig. 5 , the value of $\Gamma_{\text {hom }}$ is plotted as a function of temperature. This result was subsequently confirmed by HB experiments from the group of G. Small (Reddy et al. 1991) and by femtosecond timeresolved pump-probe experiments (Scholes and Fleming 2000; Sundström et al. 1999; Van Amerongen et al. 2000, and references therein).

Additional $\mathrm{HB}$ experiments from our laboratory on various LH2 mutants of $R b$. sphaeroides with blue-shifted B850 bands (Fowler et al. 1992) and on the B800-B820 complex of Rps. acidophila at liquid-helium temperature have shown that the transfer times from B800 to B850 vary at most between 1.7 and 2.5 ps (De Caro et al. 1994; Van der Laan et al. 1993). These results were interpreted with Förster's mechanism for energy transfer (Förster 1948, 1965), assuming that energy is transferred from the $0-0$ transition of B800 to a broad vibronic band of B850 overlapping with B800. From this model, the distance between the $\mathrm{B} 800$ donor and the $\mathrm{B} 850$ acceptor molecules was estimated to be $R_{\mathrm{DA}}=1.5-1.9 \mathrm{~nm}$ for the various LH2 complexes (Van der Laan et al. 1993). These values agreed surprisingly well with the distance of $1.76 \mathrm{~nm}$ between the B800 and B850 rings subsequently determined by X-ray crystallography (McDermott et al. 1995). Since, then, more refined methods have been developed to estimate the B800-B850 energy-transfer rates, which are based on a generalized Förster theory for multi-chromophoric 


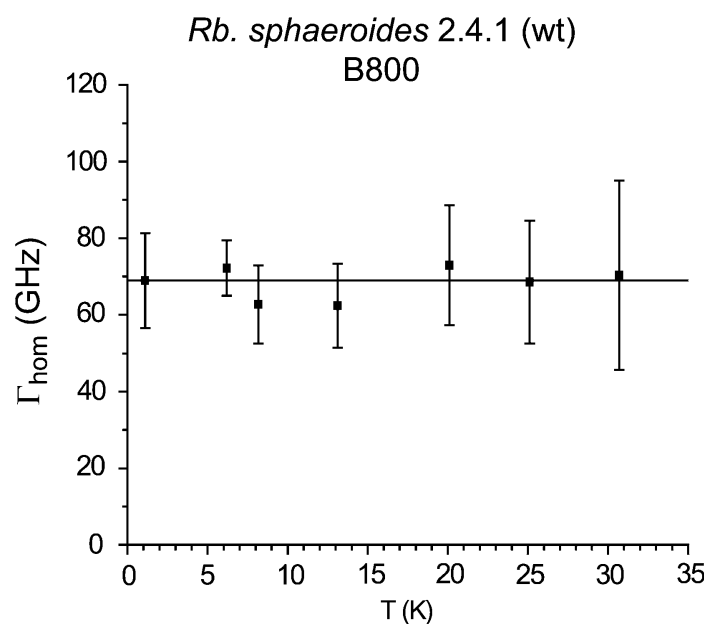

Fig. 5 Temperature dependence of the homogeneous linewidth $\Gamma_{\text {hom }}$ of the electronic transition in the red wing of the B800 band of the isolated LH2 complex of $R b$. sphaeroides $(2.4 .1, \mathrm{wt})$, between 1.2 and $30 \mathrm{~K}$. The value of $\Gamma_{\text {hom }}=69 \pm 10 \mathrm{GHz}$ is shown here to be independent of temperature. It represents the energy-transfer rate between B800 and B850 (Van der Laan et al. 1990)

systems (Beljonne et al. 2009, and references therein; Cheng and Silbey 2006; Fleming and Scholes 2004; Jang et al. 2004; Scholes and Fleming 2000, 2005) and on a modified Redfield theory (Van Grondelle and Novoderezhkin 2006, and references therein).

In our research group, not only was the inter-band B800 $\rightarrow$ B850 energy transfer studied but also the intraband $\mathrm{B} 800 \rightarrow$ B800 transfer by means of FLN and HB as a function of excitation wavelength $\lambda_{\text {exc }}$. From FLN, i.e. from the shift of narrow emission lines with $\lambda_{\mathrm{exc}}$ in the red wing of the B800 band (797-805 nm) and from the independence of the hole widths with $\lambda_{\text {exc }}$ in this spectral region, we concluded that here $\mathrm{B} 800 \rightarrow \mathrm{B} 850$ transfer dominates with $\tau_{\mathrm{B} 800 \rightarrow \mathrm{B} 850}=2.5 \pm 0.2 \mathrm{ps}$ for $R b$. sphaeroides and $2.0 \pm 0.1 \mathrm{ps}$ for Rps. acidophila at liquidhelium temperature (De Caro et al. 1994). When exciting towards the blue within the $\mathrm{B} 800$ band $\left(\lambda_{\mathrm{exc}}<798 \mathrm{~nm}\right)$, the fluorescence signals become broad and shift towards the red, while $\Gamma_{\text {hom }}$ increases from $60-80$ to $\sim 250 \mathrm{GHz}$ (between $798 \mathrm{~nm}$ and, at least, $788 \mathrm{~nm}$ ). In this spectral region, inter-band B800 $\rightarrow$ B850 competes with intra-band B800 $\rightarrow$ B800 transfer, and intra-band energy-transfer times become $\tau_{\mathrm{B} 800 \rightarrow \mathrm{B} 800} \approx 900$ fs between $\lambda_{\mathrm{exc}} \sim 780$ and $798 \mathrm{~nm}$. At $\lambda_{\text {exc }}<780 \mathrm{~nm}$, non-selective excitation in vibronic transitions of the B800 band takes place. The resulting fluorescence is broad with a peak at about $805 \mathrm{~nm}$, independent of $\lambda_{\text {exc }}$. In this region, B800 $\rightarrow$ B800 'downhill' transfer and vibrational relaxation are the dominant processes. We conclude from these examples that FLN in combination with HB are powerful techniques for unravelling energy-transfer rates in photosynthetic complexes at low temperature.

(For discussions on energy transfer in bacterial LH complexes, see also Cheng and Silbey (2006), Novoderezhkin et al. (2003), Scholes and Fleming (2000), Sundström et al. (1999), Van Amerongen et al. (2000), Wu et al. (1996) and Zazubovich et al. (2002a).)

\section{Optical dephasing in the B850 band of purple bacteria}

The strong interactions between nearest-neighbour BChl molecules in the B850 band of LH2, with distances of less than $1 \mathrm{~nm}$, lead to delocalization of the excitation to an extent that is limited by static and dynamic disorder (Cogdell et al. 2006; Hu et al. 2002; Krueger et al. 1998; Scholes et al. 1999; Sundström et al. 1999). We will come back to this subject later. Here, we discuss the role of the protein structure in controlling the excited-state dynamics of the BChl $a$ pigments in the B850 band. As shown above, the dynamics of a pigment within a protein is reflected by the homogeneous linewidth $\Gamma_{\text {hom. }}$. In the case of B800, we saw that $T_{2}^{*} \gg T_{1}$ with $\Gamma_{\text {hom }}$ determined by inter-band $(\mathrm{B} 800 \rightarrow \mathrm{B} 850)$ and intra-band (B800 $\rightarrow$ B800) energytransfer processes. Here, we will show that in the red wing of the B850 band, $\Gamma_{\text {hom }}$ is dominated by optical dephasing $\left(T_{2}^{*}\right)$ processes characterized by a value of $\Gamma_{\text {hom }}$ that is temperature dependent. Experiments were performed in our laboratory on $R b$. sphaeroides (G1C, mutant): holes were burnt at a given temperature and $\Gamma_{\text {hole }}$ measured as a function of burning-fluence density Pt/A. The hole widths are plotted versus $P t / A$ in Fig. 6a (J. Gallus and L. van den Aarssen, unpublished results). The value of $\Gamma_{\text {hom }}$ is obtained from such a plot by extrapolating $1 / 2 \Gamma_{\text {hole }}$ to $P t / A \rightarrow 0$. Similar measurements were done for temperatures between 1.2 and $4.2 \mathrm{~K}$.

Figure $6 \mathrm{~b}$ shows a plot of the homogeneous linewidth $\Gamma_{\text {hom }}$ as a function of temperature (J. Gallus and L. van den Aarssen, unpublished results). We found small values of $\Gamma_{\text {hom }}$, between $\sim 0.5 \mathrm{GHz}$ and a few $\mathrm{GHz}$ at the red wing of the B850 band, as compared to those in B800. The values in B850 are determined by 'pure' dephasing processes $\left(T_{2}^{*}\right)$, i.e. by fluctuations of the optical transition arising from coupling of the $\mathrm{BChl} a$ pigments to the surrounding protein. The values for $\mathrm{B} 800$, in contrast, are limited by $T_{1}$ processes, i.e. by energy transfer from B800 to B850 and from B800 to B800 (De Caro et al. 1994; Van der Laan et al. 1990, 1993). The temperature dependence of $\Gamma_{\text {hom }}$, in Fig. $6 \mathrm{~b}$, follows a $T^{\alpha}$ power law, with $\alpha=1.3 \pm 0.1$. Similar behaviour was found for chromophores in amorphous hosts (for reviews, see Jankowiak et al. 1993; Moerner 1988, and articles therein; Völker 1989a, 1989b), for BChl $a$ in a triethylamine glass (Van der Laan et al. 1992) and for other photosynthetic systems, 
(a) Rb. sphaeroides G1C (mutant)
B850
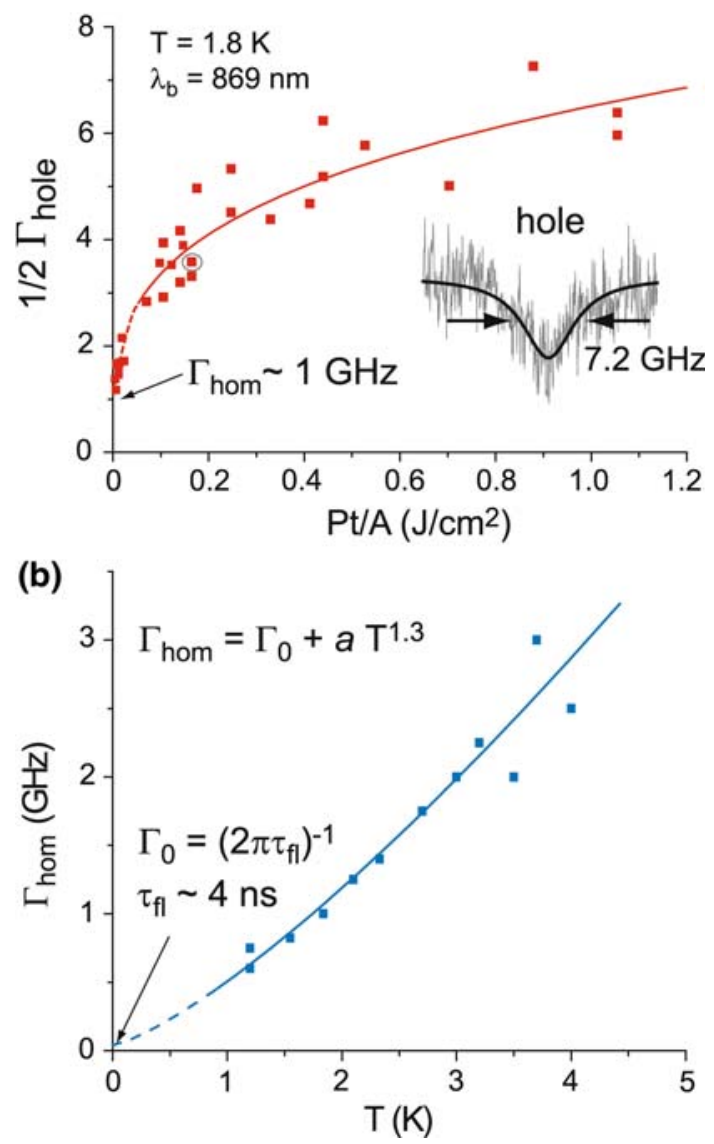

Fig. 6 Top: a Hole width, $1 / 2 \Gamma_{\text {hole, }}$ as a function of burning-fluence density, Pt/A, of a hole burnt in the red wing of the B850 band of the LH2 complex of $R b$. sphaeroides (G1C, mutant) at $1.8 \mathrm{~K}$. The extrapolation of $1 / 2 \Gamma_{\text {hole }}$ to $P t / A \rightarrow 0$ yields the homogeneous linewidth, $\Gamma_{\text {hom, }}$, at a specific temperature. Inset: Hole burnt at Pt/A $\sim 0.2 \mathrm{~J} / \mathrm{cm}^{2}$. Bottom: $\mathbf{b}$ Homogeneous linewidth, $\Gamma_{\text {hom }}$, as a function of temperature $T$ between 1.2 and $4 \mathrm{~K}$ in the red wing of the B850 band. $\Gamma_{0}$ is the residual homogeneous linewidth for $\mathrm{T} \rightarrow 0$. Its value is consistent with a fluorescence lifetime of a few nanoseconds (J. Gallus and L. van den Aarssen, unpublished results from our laboratory)

such as the B820 and B777 subunits of LH1 (Creemers and Völker 2000; Creemers et al. 1999a; Störkel et al. 1998), and the PSII RC (Den Hartog et al. 1998c, 1999b; Groot et al. 1996) and CP47-RC (Den Hartog et al. 1998b) of green plants between 1.2 and $4.2 \mathrm{~K}$. The dephasing times in photosynthetic systems, however, are about one to two orders of magnitude larger than in glassy systems, indicating that there is rather strong coupling between the pigments and protein. Here, optical dephasing is assumed to arise from coupling of the energy levels of the chromophore or pigment to a distribution of TLSs of the glassy host or protein (Jankowiak and Small 1993; Putikka and Huber 1987; Völker 1989a, b).
In contrast to the systems mentioned above, a crystalline-like $\mathrm{T}^{2 \pm 0.2}$ hole-width dependence was reported for the $\mathrm{CP} 43$ and $\mathrm{CP} 47$ 'trap' pigments in $\mathrm{O}_{2}$-evolving PSII core complexes between 2.5 and $18 \mathrm{~K}$ (Hughes et al. 2005).

The extrapolation value $\Gamma_{0}=\left(2 \pi \tau_{\mathrm{ff}}\right)^{-1}$ for $T \rightarrow 0$ in Fig. $6 \mathrm{~b}$ is consistent with a fluorescence lifetime $\tau_{\mathrm{fl}}$ of BChl $a$ of a few ns (Sundström et al. 1999). Thus, our dephasing results disprove the existence of residual exciton scattering at $T \rightarrow 0$, which was assumed to contribute to the much broader holes reported by Wu et al. (1997c) for the red wing of the B850 band of LH2 of Rps. acidophila. Although a $T^{1.3}$ dependence of $\Gamma_{\text {hom }}$ was also reported for $\mathrm{HB}$ experiments performed between 4.2 and $20 \mathrm{~K}$ (Wu et al. 1997b), the value of $\Gamma_{\text {hom }}$ at $4.2 \mathrm{~K}$ was about five times larger than the one obtained in our group at the same temperature. On the other hand, accumulated photon echo (APE) experiments on the same system (Lampoura et al. 2000) yielded values of $\Gamma_{\text {hom }}$ at $4.2 \mathrm{~K}$ that were about five times smaller than those by Wu et al. (1997b). Lampoura et al. (2000) suggested that the discrepancy between the results from the APE experiments and HB experiments was due to spectral diffusion, since the experimental time scales in APE are much smaller than those in HB (picosecond vs. minutes, respectively). However, our $\mathrm{HB}$ results at $4.2 \mathrm{~K}$ coincide with those of the APE experiments, from which we conclude that the APE-HB discrepancy does not arise from spectral diffusion, but is caused by the much too high burning fluences used in the HB experiments of $\mathrm{Wu}$ et al. (1997b). This shows that $\Gamma_{\text {hom }}$ values extracted from HB experiments are reliable only when obtained from an extrapolation of the hole width to $P t / A \rightarrow 0$, as shown in Fig. 6a and $b$.

Spectral diffusion: hole widths as a function of delay time

The dependence of spectral diffusion on the size of photosynthetic complexes

Proteins are materials that display both crystalline and glassy properties. On the one hand, they have rather welldefined tertiary structures reflected in their crystalline properties. On the other hand, and in contrast to crystals, the structures of proteins are not static: they may undergo conformational changes between a large number of somewhat different intermediates called conformational substates (CSs; Frauenfelder et al. 1991, 2001; Friedrich et al. 1994; Hofmann et al. 2003; Rutkauskas et al. 2004, 2006). These CSs are separated by a wide distribution of energy barriers with multiple minima on a potential energy landscape, reminiscent of TLSs in glasses. TLSs, however, are randomly distributed, whereas CSs are assumed to be 
hierarchically organized, possessing a large degree of complexity. Whether conformational changes in proteins have a continuous distribution of relaxation rates as observed in glasses (Koedijk et al. 1996; Littau et al. 1992; Meijers and Wiersma 1994; Silbey et al. 1996; Wannemacher et al. 1993), or are characterized by discrete and sharp rates (Thorn-Leeson and Wiersma 1995; ThornLeeson et al. 1997), is still a controversial issue (Baier et al. 2007, 2008; Schlichter and Friedrich 2001; for reviews, see Berlin et al. 2006, 2007).

One way to study the conformational dynamics of proteins is by following their time evolution through spectral diffusion (SD; Berlin et al. 2006; Creemers and Völker 2000; Den Hartog et al. 1999b; Richter et al. 2008; Schlichter and Friedrich 2001; Störkel et al. 1998). Here, we show that the size of the protein influences the amount of $\mathrm{SD}$ in photosynthetic pigment-protein complexes. We have investigated three sub-core complexes of photosystem II (PSII) of green plants (spinach) at low temperature by time-resolved spectral hole burning, covering 10 orders of magnitude in time (Den Hartog et al. 1999b; Groot et al. 1996): the isolated PSII RC, the inner core antenna CP47 and the CP47-RC complexes. The samples used in these experiments were prepared by J. Dekker and collaborators (Dekker et al. 1989, 1990; Eijckelhoff and Dekker 1995; Kwa et al. 1992). They were subsequently diluted in buffer and glycerol to work at low temperature (Den Hartog et al. 1998b).

The SD behaviour of the PSII sub-core complexes is compared here with that of B777, the monomer subunit of the LH1 complex of purple bacteria. B777 was obtained from LH1 by adding the detergent $n$-octyl- $\beta$-glucopiranoside (OG) and diluted in buffer and glycerol (Creemers et al. 1999a, and references therein). The B777 complex, in turn, is compared with BChl $a$ embedded in the same OG detergent (diluted in buffer and glycerol) without the protein, which we call here BChl $a$ in OG-glass (Creemers and Völker 2000). The purpose of this experiment was twofold, to compare the SD behaviour of proteins with that of glasses, and to clear up a long-standing problem: whether the BChl $a$ molecule in B777 is bound or not to the protein (Sturgis and Robert 1994, and references therein). HB results on SD of B820, the dimer subunit of LH1, at various temperatures and delay times, and its comparison to glasses, can be found in Störkel et al. (1998).

Photosystem II (PSII), the 'engine of life', is a large complex embedded in the thylakoid membranes of plants, algae and cyanobacteria. Driven by solar energy, PSII catalyzes the splitting of water into oxygen which is essential for the survival of life on Earth (for a review, see Barber 2008). The events that give rise to the primary and secondary electron-transfer processes, which lead to water oxidation start with the absorption of sunlight by a peripheral light-harvesting complex, called LHCII (Kühlbrandt et al. 1994), which transfers the excitation energy to the RC within the PSII core complex. The isolated PSII $\mathrm{RC}$, which is the smallest unit that shows photochemical activity (Nanba and Satoh 1987; Rhee et al. 1997), is composed of the D1 and D2 proteins and bound mainly to the CP43 and CP47 complexes (Boekema et al. 1998; Dekker and Boekema 2005). The D1 and D2 proteins contain the cofactors that bring about charge separation.

The crystal structures of cyanobacterial PSII, determined by X-ray crystallography at $3.5 \AA$ (Ferreira et al. 2004) and $3 \AA$ (Loll et al. 2005) resolution, confirmed the dimeric organization of the isolated complex and the positioning of the major subunits within each monomer, previously obtained by electron crystallography (Eijckelhoff et al. 1997; Rhee et al. 1997). Loll et al. (2005) concluded that there are about $36 \mathrm{Chl} a$ and $11 \beta$-carotene molecules per PSII core, and that the CP43 and CP47 complexes bind 13 and $16 \mathrm{Chls}$, respectively, while the RC binds $6 \mathrm{Chls}, 2$ pheophytin (Pheo) molecules, 2 plastoquinone (PQ) molecules, at least one $\beta$-carotene and a non-heme Fe. A cluster of four weakly coupled Chl $a$ molecules in the center of the $\mathrm{RC}$ forms the delocalized P680* excited state (Durrant et al. 1995), where a short-lived charge-transfer state is created before the subsequent electron-transfer processes take place. This picture is consistent with the so-called multimer models (Durrant et al. 1995; Jankowiak et al. 2002; Prokhorenko and Holzwarth 2000). Other models for energy transfer and charge separation in PSII, based on decoupled pigments with monomeric absorption, have also been reported (Diner and Rappaport 2002).

A discussion on the nature of P680 and the relation to a far red-absorbing (700-730 nm) complex that induces charge separation in intact $\mathrm{O}_{2}$-evolving PSII RCs, can be found in Hughes et al. (2005, 2006b), Krausz et al. (2008, and references therein) and Peterson-Årsköld et al. (2004).

Time-resolved HB experiments were performed, in our laboratory, in red-absorbing pigments of the isolated PSII sub-core complexes that act as 'traps' for energy transfer, i.e. in pigments characterized by a fluorescence decay time of a few nanoseconds and therefore yielding narrow holes. In the presence of SD, the holes broaden with delay time $t_{\mathrm{d}}$, the time between burning and detecting the hole. From such holes, the 'effective' homogeneous linewidth $\Gamma_{\text {hom }}^{\prime}\left(t_{\mathrm{d}}\right)$ is determined, which reflects the occurrence of timedependent conformational changes in the protein or glassy host. $\Gamma_{\text {hom }}^{\prime}\left(t_{\mathrm{d}}\right)$ can be expressed as:

$$
\begin{aligned}
\Gamma_{\text {hom }}^{\prime}\left(T, t_{\mathrm{d}}\right) & =\frac{1}{2 \pi T_{1}}+\frac{1}{\pi T_{2}^{*}\left(T, t_{\mathrm{d}}\right)} \\
& =\Gamma_{0}+\left(a_{\mathrm{PD}}+a_{\mathrm{SD}}\left(t_{\mathrm{d}}\right)\right) T^{1.3}
\end{aligned}
$$

where in the absence of energy transfer, $\Gamma_{0}$ is determined by the fluorescence lifetime $\tau_{\mathrm{fl}}, \quad \Gamma_{0}=\left(2 \pi \tau_{\mathrm{fl}}\right)^{-1}$ (see 
Creemers and Völker 2000; Den Hartog et al. 1999b; Koedijk et al. 1996; Silbey et al. 1996; Wannemacher et al. 1993). The last term in Eq. 3 consists of two contributions: a 'pure' dephasing contribution $a_{\mathrm{PD}} T^{1.3}$ (always present) that accounts for fast fluctuations of the optical transition within the lifetime of the excited state of a few ns, and a delay-time-dependent contribution determined by spectral diffusion $a_{\mathrm{SD}}\left(t_{\mathrm{d}}\right) T^{1.3}$ that increases with $t_{\mathrm{d}}$. Hence, following from Eq. 3:

$a_{\mathrm{SD}}\left(t_{\mathrm{d}}\right)=\frac{\Gamma_{\mathrm{hom}}^{\prime}\left(t_{\mathrm{d}}\right)-\Gamma_{0}}{T^{1.3}}-a_{\mathrm{PD}}$,

where the functional dependence of the coupling constant $a_{\mathrm{SD}}$ on delay time $t_{\mathrm{d}}$ yields the distribution $\mathrm{P}(\mathrm{R})$ of relaxation rates $\mathrm{R}$ in the protein (see below and Fig. 7).

The $\log -\log$ dependence of $a_{\mathrm{SD}}$ on $t_{\mathrm{d}}$ for the three subcore complexes of PSII is shown in Fig. 7, with $t_{\mathrm{d}}$ varying between $10^{-6} \mathrm{~s}$ (microseconds) and $10^{4} \mathrm{~s}$ (a few hours), and temperatures from 1.2 to $4.2 \mathrm{~K}$. The results are compared in the same figure with those obtained for B777, the

$$
\Gamma_{\text {hom }}^{\prime}\left(t_{d}\right)=\Gamma_{0}+a_{S D}\left(t_{d}\right) T^{1.3}+a_{P D} T^{1.3}
$$

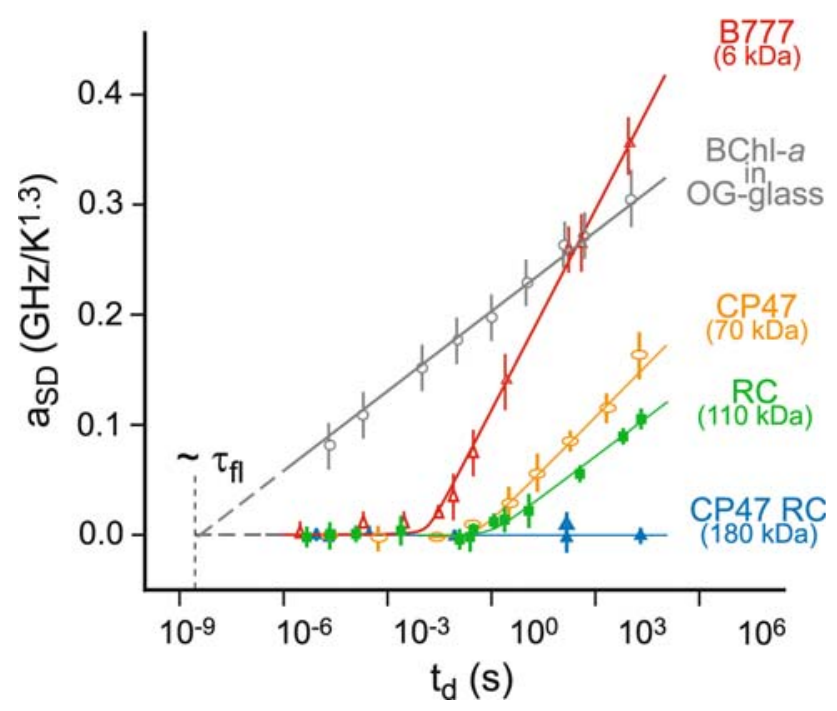

Fig. 7 Coupling constant $a_{\mathrm{SD}}$ of spectral diffusion (SD) as a function of the logarithm of the delay time between burning and probing, $t_{\mathrm{d}}$. B777-subunit of the LH1 complex of a purple bacterium (open red triangles), and three 'trap' pigments for energy transfer of the isolated PSII sub-core complexes of higher plants: CP47 (open orange ovals), $\mathrm{RC}$ (closed green squares) and CP47-RC (closed blue triangles). The data are compared to those of $\mathrm{BChl} a$ in the detergent $n$-octyl- $\beta$ glucopiranoside (OG) embedded in a buffer-glycerol glass (BChl $a$ in OG-glass; open grey circles). The mass of the protein is given in parenthesis in $\mathrm{kDa}$. Note the correlation between the amount and onset of SD and the mass of the protein: the larger the mass, the slower the SD (Den Hartog et al. 1999b). The difference between the results obtained for $\mathrm{B} 777$ and $\mathrm{BChl} a$ in OG-glass proves that the BChl $a$ molecules in B777 are bound to the protein (Creemers and Völker 2000) monomer subunit of LH1 (red curve), and BChl $a$ in OGglass (grey curve). The latter shows a typical glass-like behaviour, with $a_{\mathrm{SD}}$ increasing linearly with $\log \left(t_{\mathrm{d}}\right)$ over at least 15 orders of magnitude in time $\left(10^{-9}-10^{5} \mathrm{~s}\right)$, indicating that the distribution of relaxation rates $P(R)$ is continuous and proportional to 1/R (Koedijk et al. 1996; Silbey et al. 1996; Wannemacher et al. 1993). In contrast, the B777 subunit of $\mathrm{LH} 1$, which consists of a BChl $a$ monomer surrounded by protein and dissolved in OG-glass, qualitatively displays the behaviour of the PSII sub-core complexes: for short delay times, $a_{\mathrm{SD}}$ is constant and the results seem to be determined by 'pure' dephasing, i.e. by fast, local fluctuations. Thus, for short times, the protein appears to be rather rigid and to behave as a crystal in the direct vicinity of the excited pigments. The onset of SD at longer delay times and the logarithmic delay-time dependence of $\Gamma_{\text {hom }}^{\prime}$ suggest that slow fluctuations are involved in conformational relaxation (at least at low T), implying that protein motions have a broad and continuous $1 / \mathrm{R}$ distribution of low-frequency rates $\mathrm{R}$ with a cut-off frequency equal to $t_{\mathrm{d}}^{-1}$ at the onset of SD. These motions probably take place at the interface between the protein and bufferglycerol glass, where there is more structural flexibility.

If we take a closer look at Fig. 7, we see that the onset of $\mathrm{SD}$ as well as the slope of the curves depend on the complex studied (Den Hartog et al. 1999b). B777 (with a protein mass of $\sim 6 \mathrm{kDa}$ (Sturgis and Robert 1994)) has its onset of $\mathrm{SD}$ at the shortest delay time $\left(t_{\mathrm{d}} \sim 10 \mathrm{~ms}\right)$ and shows the largest slope $\mathrm{d} \Gamma_{\text {hom }}^{\prime} / \mathrm{d} \log t_{\mathrm{d}}$, whereas $\mathrm{CP} 47(\sim 70 \mathrm{kDa}$; Chang et al. 1994) starts SD at $t_{\mathrm{d}} \sim 300 \mathrm{~ms}$, and RC ( $\sim 110 \mathrm{kDa}$; Eijckelhoff and Dekker 1995) starts SD at $t_{\mathrm{d}} \sim 1 \mathrm{~s}$. Correspondingly, the slope of CP47 is larger than that of RC, indicating a larger amount of SD in CP47. Surprisingly, CP47-RC ( $\sim 180 \mathrm{kDa}$; Eijckelhoff et al. 1997) does not show any SD over the time and temperature ranges investigated, from which we conclude that this sample appears to be rather rigid or, at least, it does not show conformational changes at low frequencies, but only undergoes fast, crystalline-like fluctuations (i.e., dephasing) at $T \leq 4.2 \mathrm{~K}$. Thus, motions involving the entire complex (or a part of it) take place in these protein systems, even at liquid-helium temperature. It is further striking that the slopes in Fig. 7 seem to be correlated with the mass or size of the protein, and not with the number of pigments in these proteins ( 1 in B777, 8 in RC, 16 in CP47 and 24 in CP47RC). The results of Fig. 7 indicate that at low temperature and short delay times $\left(t_{\mathrm{d}}<\mathrm{ms}\right)$, there is no SD, but only 'pure' dephasing, i.e. local, fast fluctuations remain. At longer times, very slow motions (with cut-off frequencies of $1-100 \mathrm{~Hz}$ ) take place, probably at the protein-glass interface (Creemers and Völker 2000; Den Hartog et al. 1999b).

If we assume that the amount of SD is proportional to the pigment-protein interaction $\left(\propto\left(r^{n}\right)^{-1}\right.$ for multipolar 
types with $n \geq 3$ ) and to the number of TLSs present at the surface of the protein $\left(\propto r^{2}\right)$, then $\mathrm{SD} \approx \mathrm{d} \Gamma_{\text {hom }}^{\prime} / \mathrm{d} t_{\mathrm{d}} \propto$ $\left(r^{n-2}\right)^{-1} \propto r^{-1}$ (for $n=3$; Den Hartog et al. 1999b). SD should thus increase with decreasing $r$, i.e. with decreasing size of the protein (or with its mass, for constant density). In conclusion, the heavier the protein, the smaller the amount of SD. The nature of the protein motions involved, however, is still unknown and, as mentioned above, it is a matter of controversy whether TLSs are a useful concept for explaining the dynamics of proteins at low temperatures. (For recent reviews, see Berlin et al. (2006, 2007), where an anomalous power law in waiting time was observed for heme proteins at low temperature.) More time-resolved HB experiments on larger complexes, combined with different solvents, and at higher temperatures may shed some light on these unsolved issues.

Hidden spectral bands made visible: hole depth as a function of wavelength

The advantages of $\mathrm{HB}$, as compared to ultrafast timeresolved techniques, are the high spectral resolution (of a few $\mathrm{MHz}$ ) and the wavelength and burning-fluence selectivity. These properties make HB an attractive tool for disentangling spectral bands 'hidden' in strongly heterogeneously broadened and overlapping absorption bands. The disentanglement can be achieved by measuring the hole depth, in addition to the hole width, as a function of excitation wavelength, at constant (and low) burning-fluence density $(P t / A)$ and at liquid-helium temperature. Such 'action' spectra were first reported by the group of G. Small for LH1 and LH2 (Reddy et al. 1992, 1993; Wu et al. 1997a, b, c) and, subsequently, by A. Freiberg and coworkers for the same systems (Freiberg et al. 2003, 2009 and references therein; Timpmann et al. 2004), although the hole widths in these experiments were not determined by $\Gamma_{\text {hom }}$.

Holes, which do change their depth but keep their value of $\Gamma_{\text {hom }}$ constant, are a proof that only those pigments that are involved in a specific dynamic process, with a characteristic decay or dephasing time, have been selected by hole burning. Two examples from our laboratory, in which 'hidden' spectra have been made visible in this way, are presented in this review: the first example deals with 'traps' for energy transfer in PSII complexes of green plants; the second one discusses the distribution of the lowest $k=0$ exciton states in the B850 band of LH2 complexes of purple bacteria. In the first example, we show that, by means of FLN and HB, pigments within the isolated PSII $\mathrm{RC}, \mathrm{CP} 47$ and CP47-RC complexes that do not participate in energy transfer can be distinguished by their decay times from those that do participate (Den Hartog et al. 1998b). 'Trap' pigments display narrow holes because the excited pigments decay in a few nanoseconds to the ground state by fluorescence. They can be separated from the pigments that participate in energy transfer as the latter have fast excited-state decay times and, therefore, show broad and shallow holes. The spectral distribution of the depths of the narrow holes, thus, represents the distribution of 'traps' for energy transfer.

The existence of CP43- and CP47-'trap' states in $\mathrm{O}_{2}$ evolving PSII complexes has recently been reported (Hughes et al. 2005), and the assignment of the two quasidegenerate red 'trap' states in CP43 and the origin of the HB mechanism in this system is presently a matter of debate in the literature (Dang et al. 2008; Hughes et al. 2006a; Jankowiak et al. 2000).

Here, we further prove that the spectral distribution of the lowest $k=0$ exciton states within the B850 band of LH2 complexes of purple bacteria can be obtained in a manner similar to that described above: by measuring the depths of narrow holes as a function of excitation wavelength in the red wing of B850. In this case, the excited BChl $a$ molecules belonging to the lowest $k=0$ states decay directly to the ground state with a lifetime of a few nanoseconds (ns), leading to very narrow holes. Higherlying $k$-states, absorbing in the middle to the blue side of the B850 band, have many pathways of de-activation and, as a consequence, their decay times are fast, usually a few tens to hundreds of femtoseconds (fs), even at low temperature (Novoderezhkin et al. 2003; Van Grondelle and Novoderezhkin 2006, and references therein). Such fast decay times correspond to hole widths that are orders of magnitude larger than those burnt in the lowest-lying $k=0$ band. Such wide holes are usually not detectable since they are very shallow and disappear in the noise.

\section{'Traps' for energy transfer in Photosystem II complexes of green plants}

The original motivation for studying the isolated reaction center of photosystem II (PSII RC) of higher plants, the smallest unit in PSII that shows photochemical activity, called the D1-D2-cytochrome b559 complex (Nanba and Satoh 1987), was a lack of consensus in the literature regarding energy-transfer rates and charge-separation rates (Groot et al. 1994; Jankowiak et al. 1989; Klug et al. 1995; Roelofs et al. 1993; Tang et al. 1990). The controversy probably persisted because of the large overlap of strongly inhomogeneously broadened absorption bands in PSII RC between 660 and $690 \mathrm{~nm}$ (see Fig. 8a). As a consequence, sub-picosecond time-resolved experiments were difficult to interpret (Groot et al. 1996, and references therein).

To verify whether low-lying energy 'trap' pigments in PSII RC at low temperature exist, and to solve the contradictions related to energy transfer in PSII RC, spectral 


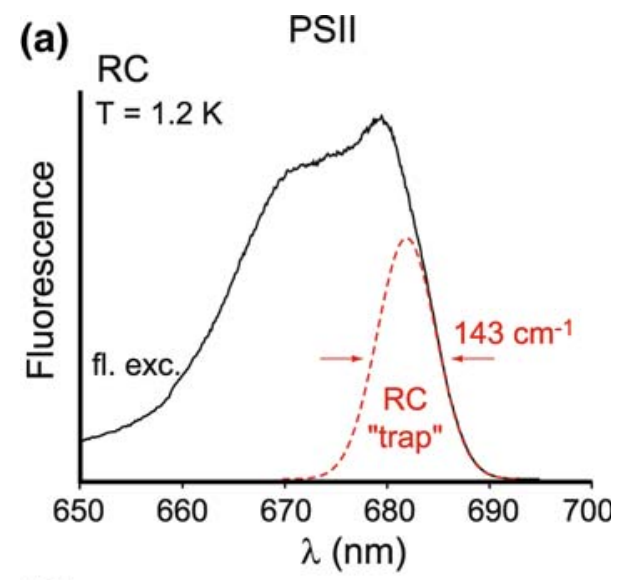

(b) $\mathrm{CP} 47$
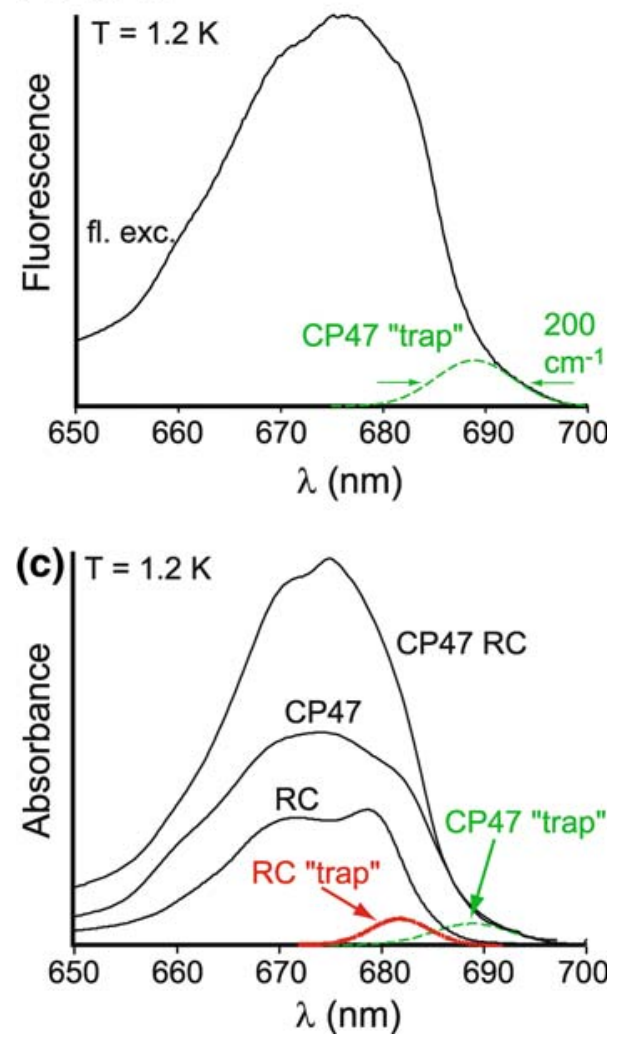

Fig. 8 Spectral distributions of 'trap' pigments for energy transfer of various isolated sub-core complexes of Photosystem II, PSII (dashed lines) obtained from hole depths measured as a function of excitation wavelength and, subsequently, reconstructed within the fluorescenceexcitation spectra. Top: a RC, Middle: b CP47, Bottom: $\mathbf{c}$ RC and CP47 'trap' distributions in the RC-, CP47- and CP47-RC-complexes of PSII. The intensities of the 'trap' distributions have been normalized to match the red wing of their respective absorption spectra. The RC and CP47 'traps' are also present in the CP47-RC complex (Den Hartog et al. 1998b; Groot et al. 1996)

hole burning experiments from 1.2 to $4.2 \mathrm{~K}$, between 665 and $690 \mathrm{~nm}$, were performed in our research group (Groot et al. 1996). Since fluorescence-excitation spectroscopy was used to probe the holes, an excited pigment can only be detected if it fluoresces or transfers its excitation energy to another pigment which in turn fluoresces. As the excited primary donor P680* undergoes very fast charge separation, in much less than 30 ps (Greenfield et al. 1996; Klug et al. 1995; Wiederrecht et al. 1994), it practically does not fluoresce. Thus, only accessory 'trap' pigments are sensitive to hole burning detected in this way.

From holes burnt in the red wing of the absorption band of PSII (between $\sim 665$ and $690 \mathrm{~nm}$ ) as a function of burning-fluence density (Pt/A) and temperature, and by extrapolation of the hole widths to $P t / A \rightarrow 0$ to obtain $\Gamma_{\text {hom }}$ and, subsequently, by extrapolation of $\Gamma_{\text {hom }}$ to $T \rightarrow 0$, hole widths were found that are limited by a fluorescence lifetime of $\sim 4 \mathrm{~ns}$. This proved that accessory pigments acting as ' $4 \mathrm{~ns}$ traps' for energy transfer are, indeed, present in PSII RC, at least at temperatures up to $4.2 \mathrm{~K}$, with dynamics controlled by 'pure' dephasing processes (Groot et al. 1996). Such 'traps' at $T<50 \mathrm{~K}$ had been previously predicted from a kinetic model (Groot et al. 1994; Roelofs et al. 1993). They were later proven to exist by FLN experiments, in addition to HB experiments (Den Hartog et al. 1998b). In contrast, Tang et al. (1990) concluded from broad holes burnt at $\sim 682 \mathrm{~nm}$ at $1.6 \mathrm{~K}$, corresponding to decay times of $50 \mathrm{ps}$, that all accessory pigments transfer their energy to P680, implying the absence of accessory 'trap' pigments in PSII RC. The accessory pigments burnt at $\sim 682 \mathrm{~nm}$ were attributed to pheophytin $a$ (Pheo $a$ ). The hole widths in these experiments had not been extrapolated to Pt/A $\rightarrow 0$.

In addition to hole widths, the spectral distribution of these 'traps' has also been determined in our laboratory by measuring the hole depth as a function of excitation wavelength at a constant, low burning-fluence density Pt/A (Groot et al. 1996). In the far red wing of the absorption band, the holes change their depth but not their width, indicating that this method indeed selects pigments involved in a specific dynamic process; here, it selects pigments decaying in $4 \mathrm{~ns}$ that do not transfer energy 'downhill'. The distribution of 'traps' in PSII RC at $1.2 \mathrm{~K}$ is illustrated in Fig. 8a. Its shape is approximately Gaussian, with a width of $\sim 143 \mathrm{~cm}^{-1}$ and a maximum at $\sim 682 \mathrm{~nm}$ (Groot et al. 1996). The linear electron-phonon coupling strength $S$ of these ' 4 ns trap' pigments was also determined by HB to be $S \sim 0.73$ (Groot et al. 1996), a value that agrees well with that reported for the Pheo $a \mathrm{Q}_{\mathrm{y}}{ }^{-}$ state by Tang et al. (1990).

The contradictions in the literature about the existence of 'traps' for energy transfer are not only valid for PSII RC but also for the CP47 and CP47-RC complexes of PSII (Den Hartog et al. 1998b, and references therein). The CP47 protein, contained within the central core of PSII and proximate to the $\mathrm{RC}$, is the last complex to be separated from the RC during isolation. It binds $16 \mathrm{Chl} a$ molecules 
(Barber 2008; Ferreira et al. 2004; Loll et al. 2005) and two $\beta$-carotenes (Chang et al. 1994). To clear up the contradictions, it was important to determine the spectral distributions of pigments hidden under the broad absorption bands of these complexes. Two types of experiments were performed for this purpose in our research group: FLN at $1.2 \mathrm{~K}$ and $\mathrm{HB}$ between 1.2 and $4.2 \mathrm{~K}$, both as a function of excitation wavelength. We will not discuss here how the results were obtained. A detailed account on the subject can be found in Den Hartog et al. (1998b), where it was shown that CP47 and CP47-RC at low temperature have distributions of pigments absorbing in their red wings (at $\sim 690 \mathrm{~nm}$ ) acting as 'traps' for the excitation energy and, therefore, do not transfer energy 'downhill'. The CP47 'trap' distribution, which has a width of $\sim 200 \mathrm{~cm}^{-1}$ and a maximum at $\sim 690 \mathrm{~nm}$, is depicted in Fig. $8 \mathrm{~b}$.

Results on CP47-RC, furthermore, suggested that the fluorescence in this complex originates from two types of 'trap' pigments, the CP47 component at $\sim 690 \mathrm{~nm}$ and the $\mathrm{RC}$ component at $\sim 682 \mathrm{~nm}$, both fluorescing independently from each other. This is shown in Fig. 8c, where the CP47-RC absorption band has been decomposed into its components, CP47 and RC, each displaying its own 'trap'. Since they fluoresce independently but have partly overlapping spectra, these two 'traps' have to be either at a distance from each other that is significantly larger than the Förster radius $\left(R_{0} \gg 3-8 \mathrm{~nm}\right)$, or they have to be in unfavourable relative orientations such that no energy transfer takes place from the RC to the CP47 complex. From the study of Den Hartog et al. (1998b), we conclude that the combination of $\mathrm{HB}$ and FLN experiments prove to be very powerful in unravelling spectral distributions of 'traps' for energy transfer in large photosynthetic complexes at liquid-helium temperatures, such as in CP47-RC, CP47 and the RC of PSII of green plants.

\section{Lowest $k=0$ exciton states in the B850 band of light-harvesting 2 complexes of purple bacteria}

We know, from X-ray crystallography, that the B850 ring of the LH2 complex of Rps. acidophila consists of 18 close-lying BChl $a$ molecules that are at distances of less than $1 \mathrm{~nm}$ from each other (McDermott et al. 1995; Papiz et al. 2003). Similar distances have been found within the B850 ring of Rs. molischianum (Koepke et al. 1996) and have been implied for $R b$. sphaeroides from cryoelectron microscopy (Walz et al. 1998). Such short distances lead to strong electronic interactions of a few $100 \mathrm{~cm}^{-1}$ and thus to delocalization of the excitation energy and the formation of coherent exciton states (Alden et al. 1997; Dahlbom et al. 2001; Freiberg et al. 1999; Hu et al. 1997, 2002; Krueger et al. 1998; Linnanto et al. 1999; Novoderezhkin et al. 1999, 2003; Sauer et al. 1996; Scholes and Fleming
2000; Scholes et al. 1999; Sundström et al. 1999; Wu et al. 1997b; Zazubovich et al. 2002b). The intensity of the B850 absorption band originates principally from two degenerate components of the excitation manifold, the $k= \pm 1$ ('allowed') states, labelled according to the assumed change in (pseudo) angular momentum. For a perfectly circular B850 ring, the excitation energy is delocalized over all 18 BChl $a$ molecules and the lowest $k=0$ exciton state is forbidden. Any deviation from this ideal situation, such as disorder, will localize the excitation energy over fewer BChl $a$ molecules, allowing $k=0$ to become (somewhat) radiative (Cheng and Silbey 2006; Freiberg et al. 1999, 2003; Hofmann et al. 2004; Jang and Silbey 2003; Jang et al. 2001; Novoderezhkin et al. 1999, 2003; Van Oijen et al. 1999; Wu et al. 1997a, b, c). The relative intensity of $k=0$ with respect to that of $k= \pm 1$ is thus a measure of the extent of disorder in the B850 ring.

The degree of excitation-energy delocalization, which is limited by static and dynamic disorder, however, remains a subject of debate. Although the majority of the calculations are based on disordered Frenkel-exciton models (for reviews, see Cogdell et al. 2006; Hu et al. 2002; Jang et al. 2001; Scholes and Fleming 2000; Van Grondelle and Novoderezhkin 2006), an alternative polaron description leading to self-trapped excitons has been put forward by Freiberg and co-workers (Freiberg and Trinkunas 2009; Freiberg et al. 2009).

Static energy disorder, which reduces the coherence length of excitons in the B850 ring, may be caused by perturbations, such as local variations in hydrogen bonding between the BChls and the polypeptides, dielectric fluctuations and structural variations. These perturbations break the symmetry of the B850 ring that, in turn, affects the degree of delocalization. It is not clear yet whether the controversial measurements reported in the literature (Freiberg et al. 2003; Ketelaars et al. 2001; Rätsep et al. 2005; Reddy et al. 1992, 1993; Timpmann et al. 2004; Wu et al. 1997a, b, c; Zazubovich et al. 2002b) are related to the different experimental procedures used and/or to the differences in the bacteria studied.

We wanted to get a better understanding of the controversies and of the interplay between the coherence of the excitation that originates from the strong electronic coupling and the energy disorder in the B850 ring that tends to destroy the coherence. To this end, we have performed experiments in our laboratory on four types of LH2 complexes of purple bacteria at low temperature with one technique, spectral HB, for comparison (L. van den Aarssen, V. Koning and N. Verhart, unpublished results). In addition, we have done simulations of the total absorption band of the B850 ring, of the lowest $k=0$ band and of their relative spectral positions and intensities (R Vlijm, L. van den Aarssen, V. Koning and N. Verhart, unpublished 
results) to test whether the assumptions made in a theoretical model developed by Silbey and collaborators (Jang et al. 2001; R. J. Silbey, personal communication) agree with the experiments. In the simulations, we have taken into account various types of static disorder, in addition to different coupling strengths and fast relaxation rates from higher-lying exciton states. Here, we focus on one system only, Rb. sphaeroides $(2.4 .1$, wt), as an example, to show how we have made visible the spectral distribution of the lowest $k=0$ exciton states, hidden under the broad B850 absorption band, by measuring the hole depth as a function of excitation wavelength.

Similar type of hole depth experiments on B850 have been reported by Freiberg et al. (2003, 2009, and references therein), and by Wu et al. (1997a, b, c) and Zabubovich et al. (2002b, and references therein). The burning-fluence densities used in the latter HB experiments, however, were more than 1,000 times larger than those used in our laboratory. Also, the detection of individual $k=0$ states by single-molecule experiments on B850 of LH2 has been reported, but not their spectral distribution (Ketelaars et al. 2001).

The B850 band of LH2 consists of a number of exciton states with their homogeneous and inhomogeneous bandwidths. The inhomogeneous bandwidth of B850 is determined by intra- and inter-complex disorder, i.e. by disorder arising from within the B850 ring and between the rings. The individual exciton bands are thus hidden in the total B850 band. To determine the position and width of the lowest $k=0$ exciton band, we first measured narrow holes of a few $\mathrm{GHz}$ with equal widths on the red wing of the B850 band at low temperature and plotted the hole width $\Gamma_{\text {hole }}$ as a function of burning-fluence density, Pt/A, (not shown). The hole widths were then extrapolated to $P t / A \rightarrow 0$ (as in Fig. 6a) at each burning wavelength $\lambda_{\text {burn }}$ to obtain the homogeneous linewidth $\Gamma_{\text {hom }}$. The depths of the narrow, homogeneously broadened holes (of equal width) at a given wavelength is proportional to the number of $\mathrm{BChl} a$ molecules contributing to the $k=0$ band at this wavelength. The dependence of the hole depth on $\lambda_{\text {burn }}$, thus, represents the distribution of the lowest $k=0$ exciton state.

The reason for the appearance of narrow holes in the red wing of the B850 band is that their width is limited by the fluorescence lifetime of a few nanoseconds of the lowest $k=0$ exciton state. In contrast, higher-lying $k$-states decay to lower-lying $k$-states in tens to hundreds of femtoseconds (Alden et al. 1997; Novoderezhkin et al. 1999, 2003; Sundström et al. 1999, and references therein), which correspond to homogeneous linewidths that are 4-5 orders of magnitude larger. They contribute to extremely broad and very shallow holes that disappear within the noise, as mentioned above. The hole depths of the narrow holes burnt in the red wing of the B850 band of $\mathrm{LH} 2$ of
$R b$. sphaeroides $(2.4 .1$, wt) are plotted as a function of burning wavelength in Fig. 9. They are well-fitted by a Gaussian curve with a width of $\sim 190 \mathrm{~cm}^{-1}$ and a maximum of $\sim 866.0 \mathrm{~nm}$. We have interpreted these data as representing the spectral distribution of the lowest $k=0$ exciton states.

In Fig. 10, the hole-depth $(k=0)$ distribution of Fig. 9 has been inserted into the B850 band. This was done by matching the red wing of the $k=0$ distribution to that of the B850 excitation spectrum. The intensity of the hole-depth distribution was scaled in such a fashion that the two red wings overlap. The result yielded a relative area of $k=0$ / B850 $\sim 9.5 \%$ and an energy difference between the two bands, $\Delta(\mathrm{B} 850-k=0) \sim 176 \mathrm{~cm}^{-1}$ for $R b$. sphaeroides (2.4.1, wt) (V. Koning and N. Verhart, unpublished results). Although the latter value is of the same order as that reported in the literature $\left(\sim 200 \mathrm{~cm}^{-1}\right)$, no values for the relative area for $R b$. sphaeroides have been published.

The four experimental parameters determined here, i.e. the widths of the $\mathrm{B} 850$ and $k=0$ bands, the energy difference, $\Delta(\mathrm{B} 850-k=0)$ and the relative area, $k=0$ / B850, were then used to find simulations that would fit the experiments. In the simulations, we have used nearestneighbour interactions of $\sim 300$ to $400 \mathrm{~cm}^{-1}$ (Cogdell et al. 2006; Jang et al. 2001; Sundström et al. 1999; Van Grondelle and Novoderezhkin 2006) and varied the amount of diagonal and off-diagonal disorder (Jang et al. 2001; R. J. Silbey, personal communication) until the calculated shapes, widths, positions and relative areas of the B850 and $k=0$ bands would coincide with the experimental ones. Figure 11 shows both simulations and the experimental

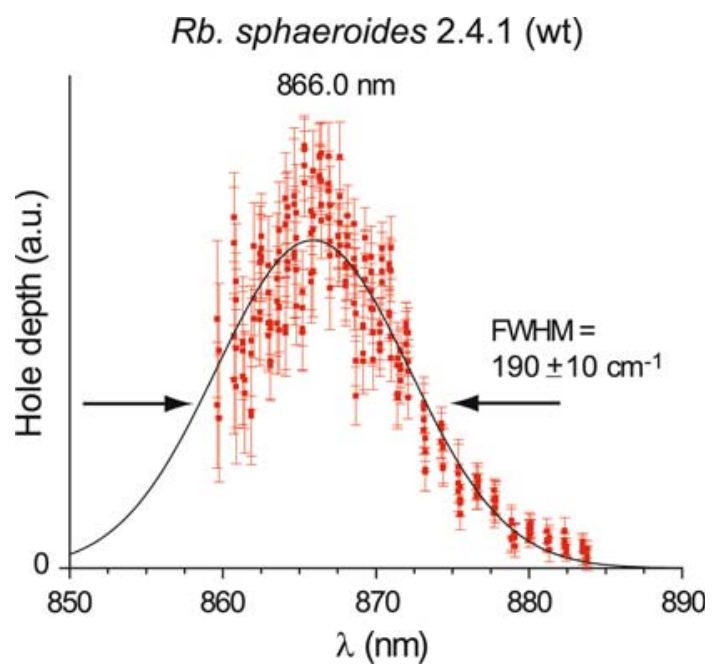

Fig. 9 Hole depth as a function of burning wavelength, for holes burnt in the red wing of the $\mathrm{B} 850$ band of $R b$. sphaeroides $(2.4 .1$, wt) at $1.2 \mathrm{~K}$. The data were fitted with a Gaussian curve (hole-depth distribution) with a maximum at $\sim 866.0 \mathrm{~nm}$ and a width of $\sim 190 \mathrm{~cm}^{-1}$ (V. Koning and N Verhart, unpublished results from our laboratory) 
Rb. sphaeroides 2.4 .1 (wt)

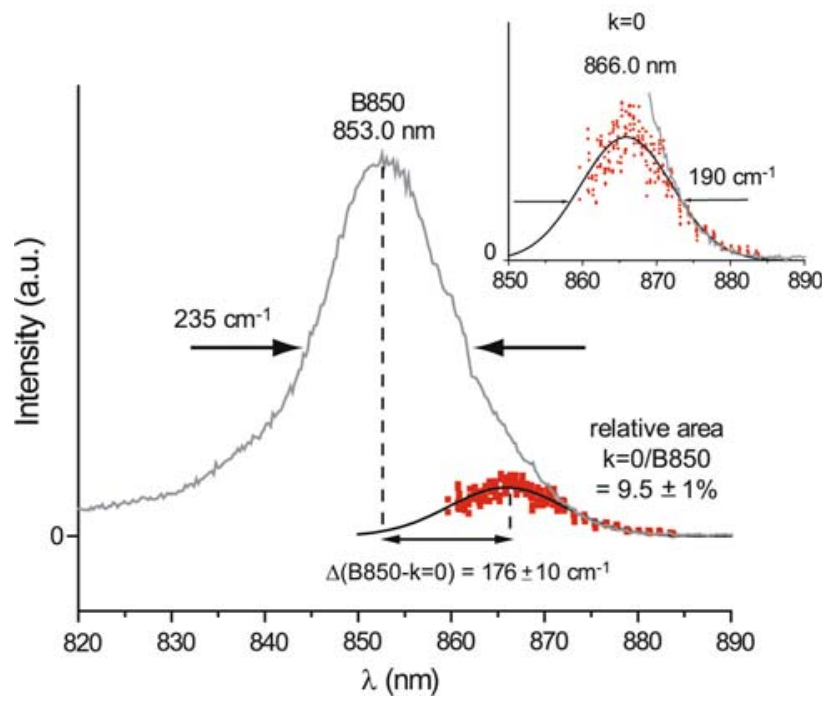

Fig. 10 Excitation spectrum of the B850 band of $R b$. sphaeroides $(2.4 .1, \mathrm{wt})$ at liquid-helium temperature with the hole-depth distribution from Fig. 9 (see also inset) built into it. The energy difference between the maxima of the B850 band and the hole-depth distribution is $\Delta(\mathrm{B} 850-k=0) \sim 176 \mathrm{~cm}^{-1}$. The relative area of the holedepth distribution with respect to that of the B850 band is $k=0 / \mathrm{B} 850 \sim 9.5 \%$ (V. Koning and N. Verhart, unpublished results from our laboratory)

results for $R b$. sphaeroides $(2.4 .1$, wt). We note that the data are well-reproduced for this complex and for a mutant, $R b$. sphaeroides (G1C) (results not shown), but are not so well-reproduced for other LH2 complexes examined in our laboratory. A detailed analysis of the data and the simulations for all the LH2 complexes of purple bacteria investigated in our research group and their comparison to data reported in the literature will be published elsewhere. With the examples presented here, we have demonstrated how hole depths measured as a function of burning wavelength can yield the spectral distribution of the lowest $k=0$ exciton states hidden inside the broad B850 absorption band containing many higher-lying $k$-states. To our knowledge, HB is the only technique that is able to make such weak, hidden exciton distributions visible.

\section{Concluding remarks}

In this review, we show that spectral hole burning in its $\mathrm{CW}$ and time-resolved versions, in combination with siteselection spectroscopy (fluorescence line-narrowing), yields quantitative information on a number of dynamic processes taking place in the electronically excited states of photosynthetic pigment-protein complexes. Using very narrow-band $(\mathrm{MHz})$, tunable, $\mathrm{CW}$ (dye, Ti:sapphire and semiconductor) lasers, it is possible to determine the
Rb. sphaeroides 2.4.1 (wt)

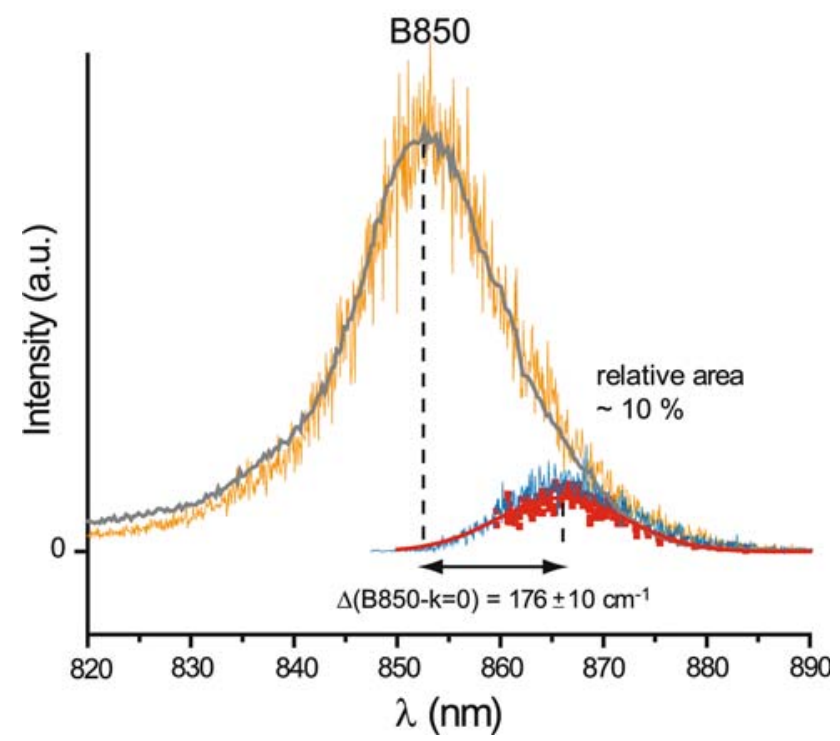

Fig. 11 Comparison of simulations, taking into account static correlated disorder (see text), with the experimental results obtained for the B850 band of $R b$. sphaeroides $(2.4 .1$, wt) at liquid-helium temperature, and the hole-depth distribution of Fig. 10. The simulation of B850 is shown in orange, while the experimental B850 is shown in grey. The simulation of the lowest $k=0$ exciton band is shown in blue, while the hole-depth distribution is shown in red. A good match between simulations and experiments was found for $R b$. sphaeroides $(2.4 .1, \mathrm{wt})$ as shown here, and for $R b$. sphaeroides (G1C, mutant) (not shown; V. Koning and N. Verhart, unpublished results from our laboratory)

homogeneous linewidth $\Gamma_{\text {hom }}$ of an optical transition that is hidden in an inhomogeneously broadened absorption band. To obtain a reliable value of $\Gamma_{\text {hom }}$, a careful measurement is required of the hole width as a function of burningfluence density $P t / A$, and an extrapolation of $\Gamma_{\text {hole }}$ to $P t /$ $A \rightarrow 0$ must be carried out.

From HB experiments performed in this way, we were able to obtain excitation energy-transfer times from $\mathrm{BChl} a$ molecules in the $\mathrm{B} 800$ ring to those in the $\mathrm{B} 850$ ring at low temperature. In addition, experiments on the red wing of the $\mathrm{B} 850$ band yielded a $T^{1.3 \pm 0.1}$ temperature dependence of $\Gamma_{\text {hom }}$ (optical dephasing), similar to organic disordered systems, and an extrapolation value of $\Gamma_{\text {hom }}$ for $T \rightarrow 0$ that is consistent with a fluorescence lifetime of the excited state of a few nanoseconds. These results proved that no scattering processes, but only decay from the excited state takes place in the red wing of B850 at $T \rightarrow 0$.

By measuring hole widths as a function of delay time between burning and probing, we are able to obtain an insight into spectral diffusion processes in photosynthetic complexes, i.e. into irreversible low-frequency fluctuations of the protein. We found that a decrease of the amount of spectral diffusion is correlated with an increase of the size of the complex for the systems studied: the B777 monomer 
subunit of bacterial LH1, and the CP47, the RC and the CP47-RC complexes of PSII of higher plants.

Furthermore, we have demonstrated that not only the hole widths but also the hole depths reveal quantitative information that is otherwise hidden within a broad absorption band. On the one hand, 'traps' for energy transfer in the isolated PSII RC, CP47 and CP47-RC complexes of higher plants could be disentangled. On the other hand, the lowest $k=0$ exciton distributions buried within the B850 band of purple bacteria were made visible.

Finally, it is worth mentioning that spectral hole burning is not only a powerful technique for studying photosynthetic complexes but its value has been demonstrated for other biological systems, such as green, yellow and red fluorescent proteins (GFPs and DsRed), also studied in our group (Bonsma et al. 2005; Creemers et al. 1999b, 2000). In these autofluorescent proteins, HB spectroscopy was used to obtain a 'fingerprint' of the species under study. For example, photo-convertible forms and their $0-0$ transitions were identified and pathways of photo-conversion and energy transfer were determined.

Owing to the wavelength selectivity of $\mathrm{HB}$, when using very narrow-band lasers, questions on the intricate electronic structure of proteins can be answered that cannot be solved with ultrafast (femtosecond) techniques, because of the inherently large optical bandwidths of short laser pulses. These two techniques are thus complementary for the study of complex biological systems.

Acknowledgements There are a number of students and postdocs from our laboratory who were involved in the experiments mentioned here (results not yet published) that we would like to thank: Jürgen Gallus, Flurin Könz, Sybrand Bonsma, Sebastian Jezowski, Rifka Vlijm, Laura van den Aarssen, Vinzenz Koning and Nico Verhart. We also thank Rienk van Grondelle (Vrije Universiteit Amsterdam, NL) and his group, and Richard Cogdell (University of Glasgow, UK) for inspiring discussions and for kindly providing us with samples. Throughout the years, we have counted on R.J. Silbey (MIT, USA) and J.H. van der Waals (Leiden University, NL) for their constructive ideas and valuable support. We further thank Govindjee not only for editing this manuscript but also for his persistence and patience with us. The study was financially supported by the Netherlands Foundation for Physical Research (FOM) and the Council for Chemical Research of the Netherlands Organisation for Scientific Research (NWO-CW).

Open Access This article is distributed under the terms of the Creative Commons Attribution Noncommercial License which permits any noncommercial use, distribution, and reproduction in any medium, provided the original author(s) and source are credited.

\section{References}

Agarwal R, Rizvi AH, Prall BS, Olsen JD, Hunter CN, Fleming GR (2002) Nature of disorder and inter-complex energy transfer in LH2 at room temperature: a three-pulse photon echo peak shift study. J Phys Chem A 106:7573-7578
Alden RG, Johnson E, Nagarajan V, Parson WW, Law CJ, Cogdell RG (1997) Calculations of spectroscopic properties of the LH2 bacteriochlorophyll-protein antenna complex from Rhodopseudomonas acidophila. J Phys Chem B 101:4667-4680

Anderson PW, Halperin BI, Varma CM (1972) Anomalous lowtemperature thermal properties of glasses and spin glasses. Philos Mag 25:1-9

Bai YS, Fayer MD (1988) Optical dephasing in glasses: theoretical comparison of the incoherent photon echo, accumulated grating echo, and two-pulse photon echo experiments. Chem Phys 128:135-155

Bai YS, Fayer MD (1989) Time scales and optical dephasing measurements: investigation of dynamics in complex systems. Phys Rev B 39:11066-11084

Baier J, Richter MF, Cogdell RJ, Oellerich S, Köhler J (2007) Do proteins at low temperature behave as glasses? A singlemolecule study. J Phys Chem B 111:1135-1138

Baier J, Richter MF, Cogdell RJ, Oellerich S, Köhler J (2008) Determination of the spectral diffusion kernel of a protein by single-molecule spectroscopy. Phys Rev Lett 100:018108-1-4

Barber J (2008) Crystal structure of the oxygen-evolving complex of photosystem II. Inorg Chem 47:1700-1710

Barkai E, Jung YJ, Silbey RJ (2004) Theory of single-molecule spectroscopy: beyond the ensemble average. Annu Rev Phys Chem 55:457-507

Beljonne D, Curutchet C, Scholes GD, Silbey RJ (2009) Beyond Förster resonance energy transfer in biological and nanoscale systems. J Phys Chem B 113:6583-6599

Berlin Y, Burin A, Friedrich J, Köhler J (2006) Spectroscopy of proteins at low temperature. Part I: experiments with molecular ensembles. Phys Life Rev 3:262-292

Berlin Y, Burin A, Friedrich J, Köhler J (2007) Low temperature spectroscopy of proteins. Part II: experiments with single protein complexes. Phys Life Rev 4:64-89

Black JL, Halperin BI (1977) Spectral diffusion, phonon echoes, and saturation recovery in glasses at low temperatures. Phys Rev B 16:2879-2895

Blankenship RE (2002) Molecular mechanisms of photosynthesis. Blackwell Science, Oxford

Boekema EJ, van Roon H, Dekker JP (1998) Specific association of photosystem II and light-harvesting complex 2 in partially solubilized photosystem II membranes. FEBS Lett 424:9599

Bonsma S, Purchase R, Jezowski S, Gallus J, Könz F, Völker S (2005) Green and red fluorescent proteins: Photo- and thermally induced dynamics probed by site-selective spectroscopy and hole burning. ChemPhysChem 6:838-849

Breinl W, Friedrich J (1988) Influence of concentration on the linewidth of spectral holes in a tetracene-doped alcohol glass. Chem Phys Lett 145:107-110

Carter TP, Small GJ (1985) Non-photochemical hole burning of chlorophyll- $a$ and chlorophyll- $b$ in polystyrene. Chem Phys Lett 120:178-182

Chang HC, Jankowiak R, Yocum CF, Picorel R, Alfonso M, Seibert M, Small GJ (1994) Exciton level structure and dynamics in the CP47 antenna complex of photosystem II. J Phys Chem 98:7717-7724

Cheng YC, Silbey RJ (2006) Coherence in the B800 ring of purple bacteria LH2. Phys Rev Lett 96:028103-1-4

Cogdell RJ, Gall A, Köhler J (2006) The architecture and function of the light-harvesting apparatus of purple bacteria: from single molecules to in vivo membranes. Q Rev Biophys 39:227-324

Creemers TMH, Völker S (2000) Dynamics of glasses and proteins probed by time-resolved hole burning. In: Gooijer C, Ariese F, Hofstraat JW (eds) Shpol'skii spectroscopy and other siteselection methods. Wiley, New York, pp 273-306 
Creemers TMH, Koedijk JMA, Chan IY, Silbey RJ, Völker S (1997) The effect of high pressure on the dynamics of doped organic glasses: a study by spectral hole-burning. J Chem Phys 107:4797-4807

Creemers TMH, De Caro C, Visschers RW, van Grondelle R, Völker S (1999a) Spectral hole burning and fluorescence line-narrowing in subunits of the light-harvesting complex LH1 of purple bacteria. J Phys Chem B 103:9770-9776

Creemers TMH, Lock AJ, Subramaniam V, Jovin TM, Völker S (1999b) Three photoconvertible forms of green fluorescent protein identified by spectral hole-burning. Nat Struct Biol 6:557-560

Creemers TMH, Lock AJ, Subramaniam V, Jovin TM, Völker S (2000) Photophysics and optical switching in green fluorescent protein mutants. Proc Natl Acad Sci USA 97:2974-2978

Dahlbom M, Pullerits T, Mukamel S, Sundström V (2001) Exciton delocalization in the B850 light-harvesting complex: comparison of different measures. J Phys Chem B 105:5515-5524

Dang NC, Zazubovich V, Reppert M, Neupane B, Picorel R, Seibert M, Jankowiak R (2008) The CP43 proximal antenna complex of higher plant photosystem II revisited: modeling and hole burning study I. J Phys Chem B 112:9921-9933

De Caro C, Visschers RW, van Grondelle R, Völker S (1994) Interband and intra-band energy transfer in LH2 antenna complexes of purple bacteria. A fluorescence line-narrowing and holeburning study. J Phys Chem 98:10584-10590

De Vries H, Wiersma DA (1976) Homogeneous broadening of optical transitions in organic mixed crystals. Phys Rev Lett 36:91-94

Dekker JP, Boekema EJ (2005) Supramolecular organization of thylakoid membrane proteins in green plants. Biochim Biophys Acta 1706:12-39

Dekker JP, Bowlby NR, Yocum CF (1989) Chlorophyll and cytochrome- $b-559$ content of the photochemical reaction center of photosystem II. FEBS Lett 254:150-154

Dekker JP, Betts SD, Yocum CF, Boekema EJ (1990) Characterization by electron microscopy of isolated particles and twodimensional crystals of the CP47-D1-D2-cyt- $b-559$ complex of photosystem II. Biochemistry 29:3220-3225

Den Hartog FTH, Bakker MP, Silbey RJ, Völker S (1998a) Long-time spectral diffusion induced by short-time energy transfer in doped glasses: concentration-, wavelength- and temperature dependence of spectral holes. Chem Phys Lett 297:314-320

Den Hartog FTH, Dekker JP, van Grondelle R, Völker S (1998b) Spectral distributions of 'trap' pigments in the RC, CP47, and CP47-RC complexes of photosystem II at low temperature: a fluorescence line-narrowing and hole-burning study. J Phys Chem B 102:11007-11016

Den Hartog FTH, Vacha F, Lock AJ, Barber J, Dekker JP, Völker S (1998c) Comparison of the excited-state dynamics of five- and six-chlorophyll photosystem II reaction center complexes. J Phys Chem B 102:9174-9180

Den Hartog FTH, van Papendrecht C, Silbey RJ, Völker S (1999a) Spectral diffusion induced by energy transfer in doped organic glasses: delay-time dependence of spectral holes. J Chem Phys 110:1010-1016

Den Hartog FTH, van Papendrecht C, Störkel U, Völker S (1999b) Protein dynamics in photosystem II complexes of green plants studied by time-resolved hole burning. J Phys Chem B 103:1375-1380

Dicker AIM, Dobkowski J, Völker S (1981) Optical dephasing of the $\mathrm{S}_{1} \leftarrow \mathrm{S}_{0}$ transition of free-base porphin in an $n$-decane host studied by photochemincal hole burning: a case of slow exchange. Chem Phys Lett 84:415-420

Diner BA, Rappaport F (2002) Structure, dynamics, and energetics of the primary photochemistry of photosystem II of oxygenic photosynthesis. Annu Rev Plant Biol 53:551-580
Durrant JR, Klug DR, Kwa SLS, van Grondelle R, Porter G, Dekker JP (1995) A multimer model for P680, the primary electron donor of photosystem II. Proc Natl Acad Sci USA 92:4798-4802

Eijckelhoff C, Dekker JP (1995) Determination of the pigment stoichiometry of the photochemical reaction center of photosystem II. Biochim Biophys Acta 1231:21-28

Eijckelhoff C, Dekker JP, Boekema EJ (1997) Characterization by electron microscopy of dimeric photosystem II core complexes from spinach with and without CP43. Biochim Biophys Acta 1321:10-20

Ferreira KN, Iverson TM, Maghlaoui K, Barber J, Iwata S (2004) Architecture of the photosynthetic oxygen-evolving center. Science 303:1831-1838

Fidder H, Wiersma DA (1993) Exciton dynamics in disordered molecular aggregates: dispersive dephasing probed by photon echo and Rayleigh scattering. J Phys Chem 97:11603-11610

Fidder H, Fowler GJS, Hunter CN, Sundström V (1998) Optical dephasing in photosynthetic pigment-protein complexes. Chem Phys 233:311-322

Fleming GR, Scholes GD (2004) Physical chemistry: quantum mechanics for plants. Nature 431:256-257

Förster T (1948) Zwischenmolekulare Energiewanderung und Fluoreszenz. Ann Phys 2:55-75

Förster T (1965) Delocalized excitation and excitation transfer. In: Sinanoglu O (ed) Modern quantum chemistry. Academic Press, New York, pp 93-137

Fowler GJS, Visschers RW, Grief GG, van Grondelle R, Hunter CN (1992) Genetically modified photosynthetic antenna complexes with blueshifted absorbance bands. Nature 355:848-850

Frauenfelder H, Sligar SG, Wolynes PG (1991) The energy landscapes and motions of proteins. Science 254:1598-1603

Frauenfelder H, McMahon BH, Austin RH, Chu K, Groves JT (2001) The role of structure, energy landscape, dynamics, and allostery in the enzymatic function of myoglobin. Proc Natl Acad Sci USA 98:2370-2374

Freiberg A, Trinkunas G (2009) Unravelling the hidden nature of antenna excitations. In: Laisk A, Nedbal L, Govindjee (eds) Photosynthesis in silico: understanding complexity from molecules to ecosystems. Springer, Berlin, pp 55-82

Freiberg A, Timpmann K, Ruus R, Woodbury NW (1999) Disordered exciton analysis of linear and nonlinear absorption spectra of antenna bacteriochlorophyll aggregates: LH2-only mutant chromatophores of Rhodobacter sphaeroides at $8 \mathrm{~K}$ under spectrally selective excitation. J Phys Chem B 103:10032-10041

Freiberg A, Rätsep M, Timpmann K, Trinkunas G (2003) Self-trapped excitons in circular bacteriochlorophyll antenna complexes. J Lumin 102:363-368

Freiberg A, Rätsep M, Timpmann K, Trinkunas G (2009) Excitonic polarons in quasi-one-dimensional LH1 and LH2 bacteriochlorophyll $a$ antenna aggregates from photosynthetic bacteria: a wavelength-dependent selective spectroscopy study. Chem Phys 357:102-112

Friedrich J, Haarer D (1986) Structural relaxation processes in polymers and glasses as studied by high-resolution optical spectroscopy. In: Zschokke I (ed) Optical spectroscopy of glasses. Reidel, Dordrecht, pp 149-198

Friedrich J, Gafert J, Zollfrank J, Vanderkooi J, Fidy J (1994) Spectral hole burning and selection of conformational substates in chromoproteins. Proc Natl Acad Sci USA 91:1029-1033

Gillie JK, Lyle PA, Small GJ, Golbeck JH (1989) Spectral hole burning of the primary electron-donor state of photosystem I. Photosynth Res 22:233-246

Gooijer C, Ariese F, Hofstraat JW (eds) (2000) Shpol'skii spectroscopy and other site-selection methods. Wiley, New York 
Gorokhovskii AA, Kaarli RK, Rebane LA (1974) Hole burning in the contour of a pure electronic line in a Shpol'skii system. JETP Lett 20:216-218

Greenfield SR, Seibert M, Govindjee, Wasielewski MR (1996) Wavelength and intensity dependent primary photochemistry of isolated photosystem II reaction centers at $5^{\circ} \mathrm{C}$. Chem Phys 210:279-295

Groot ML, Peterman EJG, van Kan PJM, van Stokkum IHN, Dekker JP, van Grondelle R (1994) Temperature-dependent triplet and fluorescence quantum yields of the photosystem II reaction center described in a thermodynamic model. Biophys J 67:318-330

Groot ML, Dekker JP, van Grondelle R, den Hartog FTH, Völker S (1996) Energy transfer and trapping in isolated photosystem II reaction centers of green plants at low temperature. A study by spectral hole burning. J Phys Chem 100:11488-11495

Hayes JM, Small GJ (1978) Non-photochemical hole burning and impurity site-relaxation processes in organic glasses. Chem Phys 27:151-157

Hayes JM, Small GJ (1986) Photochemical hole burning and strong electron-phonon coupling: primary donor states of reaction centers of photosynthetic bacteria. J Phys Chem 90:4928-4931

Hesselink WH, Wiersma DA (1980) Optical dephasing and vibronic relaxation in molecular mixed crystals: a picosecond photon echo and optical study of pentacene in naphthalene and $p$ terphenyl. J Chem Phys 73:648-663

Hesselink WH, Wiersma DA (1983) Theory and experimental aspects of photon echoes in molecular solids. In: Agranovich VM, Hochstrasser RM (eds) Spectroscopy and excitation dynamics of condensed molecular systems. North Holland, Amsterdam, pp 249-299

Hofmann C, Aartsma TJ, Michel H, Köhler J (2003) Direct observation of tiers in the energy landscape of a chromoprotein: a singlemolecule study. Proc Natl Acad Sci USA 100:15534-15538

Hofmann C, Aartsma TJ, Köhler J (2004) Energetic disorder and the B850-exciton states of individual light-harvesting 2 complexes from Rhodopseudomonas acidophila. Chem Phys Lett 395:373378

Hu P, Walker LR (1977) Spectral diffusion in glasses at lowtemperatures. Solid State Commun 24:813-816

Hu P, Walker LR (1978) Spectral-diffusion decay in echo experiments. Phys Rev B 18:1300-1305

Hu XC, Ritz T, Damjanovic A, Schulten K (1997) Pigment organization and transfer of electronic excitation in the photosynthetic unit of purple bacteria. J Phys Chem B 101:3854-3871

Hu XC, Ritz T, Damjanovic A, Autenrieth F, Schulten K (2002) Photosynthetic apparatus of purple bacteria. Q Rev Biophys 35:1-62

Huber DL (1987) Analysis of a stochastic model for the optical linewidths and photon-echo decays of impurities in glasses. J Lumin 36:307-314

Hughes JL, Krausz E, Smith PJ, Pace RJ, Riesen H (2005) Probing the lowest energy chlorophyll $a$ states of photosystem II via selective spectroscopy: new insights on P680. Photosynth Res 84:93-98

Hughes JL, Picorel R, Seibert M, Krausz E (2006a) Photophysical behavior and assignment of the low-energy chlorophyll states in the CP43 proximal antenna protein of higher plant photosystem II. Biochemistry 45:12345-12357

Hughes JL, Smith P, Pace R, Krausz E (2006b) Charge separation in photosystem II core complexes induced by $690-730 \mathrm{~nm}$ excitation at $1.7 \mathrm{~K}$. Biochim Biophys Acta 1757:841-851

Jang SJ, Silbey RJ (2003) Single complex line shapes of the B850 band of LH2. J Chem Phys 118:9324-9336

Jang SJ, Dempster SE, Silbey RJ (2001) Characterization of the static disorder in the B850 band of LH2. J Phys Chem B 105:66556665
Jang SJ, Newton MD, Silbey RJ (2004) Multichromophoric Förster resonance energy transfer. Phys Rev Lett 92:218301-1-4

Jankowiak R (2000) Fundamental aspects of fluorescence linenarrowing. In: Gooijer C, Ariese F, Hofstraat JW (eds) Shpol'skii spectroscopy and other site-selection methods. Wiley, New York, pp 235-272

Jankowiak R, Small GJ (1987) Hole-burning spectroscopy and relaxation dynamics of amorphous solids at low temperatures. Science 237:618-625

Jankowiak R, Small GJ (1993) Origin of the $\mathrm{T}^{1.3}$ power law of pure dephasing for impurity electronic transitions in amorphous solids. Chem Phys Lett 207:436-442

Jankowiak R, Small GJ, Athreya KB (1986) Derivation of the density of states and distribution functions for two-level systems in glasses. J Phys Chem 90:3896-3898

Jankowiak R, Tang D, Small GJ, Seibert M (1989) Transient and persistent hole burning of the reaction center of photosystem II. J Phys Chem 93:1649-1654

Jankowiak R, Hayes JM, Small GJ (1993) Spectral hole-burning spectroscopy in amorphous molecular solids and proteins. Chem Rev 93:1471-1502

Jankowiak R, Zazubovich V, Rätsep M, Matsuzaki S, Alfonso M, Picorel R, Seibert M, Small GJ (2000) The CP43 core antenna complex of photosystem II possesses two quasi-degenerate and weakly coupled Qy-trap states. J Phys Chem B 104:1180511815

Jankowiak R, Hayes JM, Small GJ (2002) An excitonic pentamer model for the core Qy states of the isolated photosystem II reaction center. J Phys Chem B 106:8803-8814

Jimenez R, van Mourik F, Yu JY, Fleming GR (1997) Three-pulse photon echo measurements on LH1 and LH2 complexes of Rhodobacter sphaeroides: A nonlinear spectroscopic probe of energy transfer. J Phys Chem B 101:7350-7359

Ketelaars M, van Oijen AM, Matsushita M, Köhler J, Schmidt J, Aartsma TJ (2001) Spectroscopy on the B850 band of individual light-harvesting 2 complexes of Rhodopseudomonas acidophila I. Experiments and Monte Carlo simulations. Biophys J 80:1591-1603

Kharlamov BM, Personov RI, Bykovska LA (1974) Stable gap in absorption spectra of solid solutions of organic molecules by laser irradiation. Opt Commun 12:191-193

Klug DR, Rech T, Joseph DM, Barber J, Durrant JR, Porter G (1995) Primary processes in isolated photosystem II reaction centers probed by magic-angle transient absorption spectroscopy. Chem Phys 194:433-442

Koedijk JMA, Wannemacher R, Silbey RJ, Völker S (1996) Spectral diffusion in organic glasses: time dependence of spectral holes. J Phys Chem 100:19945-19953

Koepke J, Hu XC, Muenke C, Schulten K, Michel H (1996) The crystal structure of the light-harvesting complex 2 (B800-850) from Rhodospirillum molischianum. Structure 4:581-597

Köhler W, Friedrich J, Fischer R, Scheer H (1988) An optical linewidth study of a chromoprotein: C-phycocyanin in a lowtemperature glass. Chem Phys Lett 146:280-282

Krausz E, Cox N, Peterson-Årsköld S (2008) Spectral characteristics of PS II reaction centres: as isolated preparations and when integral to PS II core complexes. Photosynth Res 98:207-217

Krueger BP, Scholes GD, Fleming GR (1998) Calculation of couplings and energy-transfer pathways between the pigments of LH2 by the ab initio transition density cube method. J Phys Chem B 102:5378-5386

Kühlbrandt W, Wang DN, Fujiyoshi Y (1994) Atomic model of plant light-harvesting complex by electron crystallography. Nature 367:614-621

Kwa SLS, Newell WR, van Grondelle R, Dekker JP (1992) The reaction center of photosystem II studied with polarized 
fluorescence spectroscopy. Biochim Biophys Acta 1099:193202

Lampoura SS, van Grondelle R, van Stokkum IHN, Cogdell RJ, Wiersma DA, Duppen K (2000) Exciton dynamics in LH1 and LH2 of Rhodopseudomonas acidophila and Rhodobium marinum probed with accumulated photon-echo and pump-probe measurements. J Phys Chem B 104:12072-12078

Linnanto J, Korppi-Tommola JEI, Helenius VM (1999) Electronic states, absorption spectrum and circular dichroism spectrum of the photosynthetic bacterial LH2 antenna of Rhodopseudomonas acidophila as predicted by exciton theory and semi-empirical calculations. J Phys Chem B 103:8739-8750

Littau KA, Dugan MA, Chen S, Fayer MD (1992) Dynamics in a lowtemperature glass: fast generation and detection of optical holes. J Chem Phys 96:3484-3494

Lock AJ, Creemers TMH, Völker S (1999) Spectral diffusion in glasses under high pressure: a study by time-resolved holeburning. J Chem Phys 110:7467-7473

Loll B, Kern J, Saenger W, Zouni A, Biesiadka J (2005) Towards complete cofactor arrangement in the $3.0 \AA$ resolution structure of photosystem II. Nature 438:1040-1044

Lyle PA, Kolaczkowski SV, Small GJ (1993) Photochemical holeburned spectra of protonated and deuterated reaction centers of Rhodobacter sphaeroides. J Phys Chem 97:6924-6933

Maynard R, Rammal R, Suchail R (1980) Spectral diffusion decay of spontaneous echoes in disordered systems. J Phys Lett 41:L291L294

McDermott G, Prince SM, Freer AA, Hawthornthwaite-Lawless AM, Papiz MZ, Cogdell RJ, Isaacs NW (1995) Crystal structure of an integral membrane light-harvesting complex from photosynthetic bacteria. Nature 374:517-521

Meijers HC, Wiersma DA (1994) Low-temperature dynamics in amorphous solids: a photon-echo study. J Chem Phys 101:69276943

Moerner WE (ed) (1988) Persistent spectral hole burning: science and applications. Springer, Berlin

Moerner WE (2002) A dozen years of single-molecule spectroscopy in physics, chemistry, and biophysics. J Phys Chem B 106:910927

Moerner WE, Kador L (1989) Optical detection and spectroscopy of single molecules in a solid. Phys Rev Lett 62:2535-2538

Molenkamp LW, Wiersma DA (1984) Optical dephasing by uncorrelated phonon scattering to librations. An optical and picosecond photon-echo study of a photosite of pentacene in benzoic acid. J Chem Phys 80:3054-3063

Morsink JBW, Aartsma TJ, Wiersma DA (1977) Photon-echo relaxation measurements with two dye lasers: application to pentacene- $\mathrm{h}_{14}$ and $-\mathrm{d}_{14}$ in $p$-terphenyl-h crystals at $1.5 \mathrm{~K}$. Chem Phys Lett 49:34-38

Nanba O, Satoh K (1987) Isolation of a photosystem II reaction center consisting of D1 and D2 polypeptides and cytochrome $b-559$. Proc Natl Acad Sci USA 84:109-112

Narasimhan LR, Pack DW, Fayer MD (1988) Solute-solvent dynamics and interactions in glassy media: photon echo and optical hole burning studies of cresyl violet in ethanol glass. Chem Phys Lett 152:287-293

Novoderezhkin V, Monshouwer R, van Grondelle R (1999) Exciton (de)localization in the LH2 antenna of Rhodobacter sphaeroides as revealed by relative difference-absorption measurements of the LH2 antenna and the B820 subunit. J Phys Chem B 103:10540-10548

Novoderezhkin V, Wendling M, van Grondelle R (2003) Intra- and inter-band transfers in the B800-B850 antenna of Rhodospirillum molischianum: Redfield theory modeling of polarized pumpprobe kinetics. J Phys Chem B 107:11534-11548
Orrit M, Bernard J (1990) Single pentacene molecules detected by fluorescence excitation in a $p$-terphenyl crystal. Phys Rev Lett 65:2716-2719

Papiz MZ, Prince SM, Howard T, Cogdell RJ, Isaacs NW (2003) The structure and thermal motion of the B800-850 LH2 complex from Rps. acidophila at $2.0 \AA$ resolution and $100 \mathrm{~K}$ : new structural features and functionally relevant motions. J Mol Biol 326: $1523-1538$

Personov RI (1983) Site selection spectroscopy of complex molecules and its applications. In: Agranovich VM, Hochstrasser RM (eds) Spectroscopy and excitation dynamics of condensed molecular systems. North-Holland, Amsterdam, pp 555-619

Personov RI, Al'shits EI, Bykovskaya LA (1972) The effect of fine structure appearance in laser-excited fluorescence spectra of organic compounds in solid solutions. Opt Commun 6:169-173

Peterman EJG, Pullerits T, van Grondelle R, van Amerongen $\mathrm{H}$ (1997) Electron-phonon coupling and vibronic fine structure of light-harvesting complex II of green plants: temperature dependent absorption and high-resolution fluorescence spectroscopy. J Phys Chem B 101:4448-4457

Peterson-Årsköld S, Prince BJ, Krausz E, Smith PJ, Pace RJ, Picorel R, Seibert M (2004) Low-temperature spectroscopy of fully active PSII cores. Comparisons with CP43, CP47, D1-D2-cyt- $b$ 559 fragments. J Lumin 108:97-100

Phillips WA (1972) Tunneling states in amorphous solids. J Low Temp Phys 7:351-360

Phillips WA (1981) Amorphous solids: low temperature properties. Springer, Berlin

Phillips WA (1987) Two-level states in glasses. Rep Prog Phys 50:1657-1708

Prokhorenko VI, Holzwarth AR (2000) Primary processes and structure of the photosystem II reaction center: a photon echo study. J Phys Chem B 104:11563-11578

Putikka WO, Huber DL (1987) Optical linewidths and photon-echo decays of impurities in glasses. Phys Rev B 36:3436-3441

Rätsep M, Hunter CN, Olsen JD, Freiberg A (2005) Band structure and local dynamics of excitons in bacterial light-harvesting complexes revealed by spectrally selective spectroscopy. Photosynth Res 86:37-48

Reddy NRS, Small GJ, Seibert M, Picorel R (1991) Energy-transfer dynamics of the B800-B850 antenna complex of Rhodobacter sphaeroides: a hole burning study. Chem Phys Lett 181:391-399

Reddy NRS, Picorel R, Small GJ (1992) B896 and B870 components of the Rhodobacter sphaeroides antenna: a hole burning study. $\mathrm{J}$ Phys Chem 96:6458-6464

Reddy NRS, Cogdell RJ, Zhao L, Small GJ (1993) Non-photochemical hole burning of the B800-B850 antenna complex of Rhodopseudomonas acidophila. Photochem Photobiol 57:35-39

Reinot T, Zazubovich V, Hayes JM, Small GJ (2001) New insights on persistent non-photochemical hole burning and its application to photosynthetic complexes. J Phys Chem B 105:5083-5098

Rhee KH, Morris EP, Zheleva D, Hankamer B, Kühlbrandt W, Barber J (1997) Two-dimensional structure of plant photosystem II at 8 A resolution. Nature 389:522-526

Richter MF, Baier J, Southall J, Cogdell RJ, Oellerich S, Köhler J (2008) Spectral diffusion of the lowest exciton component in the core complex from Rhodopseudomonas palustris studied by single-molecule spectroscopy. Photosynth Res 95:285-290

Rigler R, Orrit M, Basché T (eds) (2001) Single-molecule spectroscopy. Springer, Berlin

Roelofs TA, Kwa SLS, van Grondelle R, Dekker JP, Holzwarth AR (1993) Primary processes and structure of the photosystem II reaction center: II. Low-temperature picosecond fluorescence kinetics of a D1-D2-cyt- $b$-559 reaction-center complex isolated by short Triton exposure. Biochim Biophys Acta 1143:147-157 
Rutkauskas D, Novoderezkhin V, Cogdell RJ, van Grondelle R (2004) Fluorescence spectral fluctuations of single $\mathrm{LH} 2$ complexes from Rhodopseudomonas acidophila strain 10050. Biochemistry 43:4431-4438

Rutkauskas D, Olsen J, Gall A, Cogdell RJ, Hunter CN, van Grondelle R (2006) Comparative study of spectral flexibilities of bacterial light-harvesting complexes: structural implications. Biophys J 90:2463-2474

Sauer K, Cogdell RJ, Prince SM, Freer A, Isaacs NW, Scheer H (1996) Structure-based calculations of the optical spectra of the LH2 bacteriochlorophyll-protein complex from Rhodopseudomonas acidophila. Photochem Photobiol 64:564-576

Schlichter J, Friedrich J (2001) Glasses and proteins: similarities and differences in their spectral diffusion dynamics. J Chem Phys 114:8718-8721

Scholes GD, Fleming GR (2000) On the mechanism of light harvesting in photosynthetic purple bacteria: B800 to B850 energy transfer. J Phys Chem B 104:1854-1868

Scholes GD, Fleming GR (2005) Energy transfer and photosynthetic light harvesting. Adv Chem Phys 132:57-130

Scholes GD, Gould IR, Cogdell RJ, Fleming GR (1999) Ab initio molecular orbital calculations of electronic couplings in the LH2 bacterial light-harvesting complex of Rps acidophila. J Phys Chem B 103:2543-2553

Silbey RJ, Koedijk JMA, Völker S (1996) Time- and temperature dependence of optical linewidths in glasses at low temperature: spectral diffusion. J Chem Phys 105:901-909

Small GJ (1983) Persistent non-photochemical hole burning and the dephasing of impurity electronic transitions in organic glasses. In: Agranovich VM, Hochstrasser RM (eds) Spectroscopy and excitation dynamics of condensed molecular systems. NorthHolland, Amsterdam, pp 515-554

Störkel U, Creemers TMH, Den Hartog FTH, Völker S (1998) Glass versus protein dynamics at low temperature studied by timeresolved spectral hole burning. J Lumin 76, 77:327-330

Sturgis JN, Robert B (1994) Thermodynamics of membrane polypeptide oligomerization in light-harvesting complexes and associated structural changes. J Mol Biol 238:445-454

Sundström V, Pullerits T, van Grondelle R (1999) Photosynthetic light-harvesting: reconciling dynamics and structure of purple bacterial LH2 reveals function of photosynthetic unit. J Phys Chem B 103:2327-2346

Tang D, Jankowiak R, Gillie JK, Small GJ, Tiede DM (1988) Structured hole-burned spectra of reaction centers of Rhodopseudomonas viridis. J Phys Chem 92:4012-4015

Tang D, Jankowiak R, Seibert M, Yocum CF, Small GJ (1990) Excited-state structure and energy-transfer dynamics of two different preparations of the reaction center of photosystem II: a hole-burning study. J Phys Chem 94:6519-6522

Thijssen HPH, Dicker AIM, Völker S (1982) Optical dephasing in free-base porphin in organic glasses: a study by photochemical hole-burning. Chem Phys Lett 92:7-12

Thijssen HPH, van den Berg R, Völker S (1983) Thermal broadening of optical homogeneous linewidths in organic glasses and polymers studied via photochemical hole-burning. Chem Phys Lett 97:295-302

Thijssen HPH, van den Berg R, Völker S (1985) Optical relaxation in organic disordered systems submitted to photochemical and nonphotochemical hole-burning. Chem Phys Lett 120:503-508

Thorn-Leeson D, Wiersma DA (1995) Real-time observation of lowtemperature protein motions. Phys Rev Lett 74:2138-2141

Thorn-Leeson D, Wiersma DA, Fritsch K, Friedrich J (1997) The energy landscape of myoglobin: an optical study. J Phys Chem B 101:6331-6340

Timpmann K, Rätsep M, Hunter CN, Freiberg A (2004) Emitting excitonic polaron states in core LH1 and peripheral LH2 bacterial light-harvesting complexes. J Phys Chem B 108:10581-10588

Van Amerongen H, Valkunas L, van Grondelle R (2000) Photosynthetic excitons. World Scientific, Singapore. ISBN 981-02-3280-2

Van den Berg R, Völker S (1986) Does non-photochemical hole burning reflect optical dephasing processes in amorphous materials? Pentacene in polymethylmethacrylate as an affirmative example. Chem Phys Lett 127:525-533

Van den Berg R, Völker S (1987) Optical homogeneous linewidths of resorufin in ethanol glass: an apparent contradiction between holeburning and photon-echo results. Chem Phys Lett 137:201-208

Van den Berg R, Visser A, Völker S (1988) Optical dephasing in organic glasses between $0.3 \mathrm{~K}$ and $20 \mathrm{~K}$. A hole-burning study of resorufin and free-base porphin. Chem Phys Lett 144:105-113

Van der Laan H, Schmidt T, Visschers RW, Visscher KJ, van Grondelle R, Völker S (1990) Energy transfer in the B800-850 antenna complex of purple bacteria Rhodobacter sphaeroides: a study by spectral hole-burning. Chem Phys Lett 170:231-238

Van der Laan H, Smorenburg HE, Schmidt T, Völker S (1992) Permanent hole burning with a diode laser: excited-state dynamics of bacteriochlorophyll in glasses and micelles. J Opt Soc Am B 9:931-940

Van der Laan H, De Caro C, Schmidt T, Visschers RW, van Grondelle R, Fowler GJS, Hunter CN, Völker S (1993) Excitedstate dynamics of mutated antenna complexes of purple bacteria studied by hole burning. Chem Phys Lett 212:569-580

Van Grondelle R, Novoderezhkin VI (2006) Energy transfer in photosynthesis: experimental insights and quantitative models. Phys Chem Chem Phys 8:793-807

Van Grondelle R, Dekker JP, Gillbro T, Sundström V (1994) Energy transfer and trapping in photosynthesis. Biochim Biophys Acta 1187:1-65

Van Oijen AM, Ketelaars M, Köhler J, Aartsma TJ, Schmidt J (1999) Unraveling the electronic structure of individual photosynthetic pigment-protein complexes. Science 285:400-402

Völker S (1989a) Hole-burning spectroscopy. Annu Rev Phys Chem 40:499-530

Völker S (1989b) Spectral hole burning in crystalline and amorphous organic solids. Optical relaxation processes at low temperature. In: Fünfschilling $\mathbf{J}$ (ed) Relaxation processes in molecular excited states. Kluwer, Dordrecht, pp 113-242

Völker S, Macfarlane RM (1979) Photochemical hole burning in freebase porphyrin and chlorin in $n$-alkane matrices. IBM J Res Develop 23:547-555

Völker S, van der Waals JH (1976) Laser-induced photochemical isomerization of free base porphyrin in an $n$-octane crystal at 4.2 K. Mol Phys 32:1703-1718

Völker S, Macfarlane RM, Genack AZ, Trommsdorf HP, van der Waals JH (1977) Homogeneous linewidth of the $S_{1} \leftarrow S_{0}$ transition of free-base porphyrin in an $n$-octane crystal as studied by photochemical hole-burning. J Chem Phys 67:17591765

Völker S, Macfarlane RM, van der Waals JH (1978) Frequency shift and dephasing of $S_{1} \leftarrow S_{0}$ transition of free-base porphin in an $n$-octane crystal as a function of temperature. Chem Phys Lett 53:8-13

Walz T, Jamieson SJ, Bowers CM, Bullough PA, Hunter CN (1998) Projection structures of three photosynthetic complexes from Rhodobacter sphaeroides: LH2 at $6 \AA$, LH1 and RC-LH1 at 25 A. J Mol Biol 282:833-845

Wannemacher R, Koedijk JMA, Völker S (1993) Spectral diffusion in organic glasses. Temperature dependence of permanent and transient holes. Chem Phys Lett 206:1-8

Wiederrecht GP, Seibert M, Govindjee, Wasielewski MR (1994) Femtosecond photodichroism studies of isolated photosystem II reaction centers. Proc Natl Acad Sci USA 91:8999-9003 
Wiersma DA, Duppen K (1987) Picosecond holographic-grating spectroscopy. Science 237:1147-1154

Wu HM, Savikhin S, Reddy NRS, Jankowiak R, Cogdell RJ, Struve WS, Small GJ (1996) Femtosecond and hole-burning studies of B800's excitation energy relaxation dynamics in the LH2 antenna complex of Rhodopseudomonas acidophila (strain 10050). J Phys Chem 100:12022-12033

Wu HM, Rätsep M, Jankowiak R, Cogdell RJ, Small GJ (1997a) Comparison of the LH2 antenna complexes of Rhodopseudomonas acidophila (strain 10050) and Rhodobacter sphaeroides by high-pressure absorption, high-pressure hole burning, and temperature-dependent absorption spectroscopies. J Phys Chem B 101:7641-7653

Wu HM, Rätsep M, Lee IJ, Cogdell RJ, Small GJ (1997b) Exciton level structure and energy disorder of the B850 ring and the $\mathrm{LH} 2$ antenna complex. J Phys Chem B 101:7654-7663
Wu HM, Reddy NRS, Small GJ (1997c) Direct observation and hole burning of the lowest exciton level (B870) of the LH2 antenna complex of Rhodopseudomonas acidophila (strain 10050). J Phys Chem B 101:651-656

Yang M, Fleming GR (1999) Third-order nonlinear optical response of energy transfer systems. J Chem Phys 111:27-39

Zazubovich V, Jankowiak R, Small GJ (2002a) On B800 $\rightarrow$ B800 energy transfer in the LH2 complex of purple bacteria. J Lumin 98:123-129

Zazubovich V, Jankowiak R, Small GJ (2002b) A high-pressure spectral hole burning study of correlation between energy disorder and excitonic couplings in the LH2 complex from Rhodopseudomonas acidophila. J Phys Chem B 106:6802-6814 